\title{
Environmental Resistance of Oxide Tags Fabricated on 304L Stainless Steel via Nanosecond Pulsed Laser Irradiation
}

\author{
Samantha K. Lawrence ${ }^{1 \#}$, David P. Adams ${ }^{2}$, David F. Bahr ${ }^{1 *}$, Neville R. Moody ${ }^{3}$ \\ ${ }^{1}$ School of Materials Engineering, Purdue University, 701 West Stadium Ave. West Lafayette, IN 47907, USA \\ ${ }^{2}$ Sandia National Laboratories, 1515 Eubank SE Albuquerque, NM 87123, USA \\ ${ }^{3}$ Sandia National Laboratories, 7011 East Ave. Livermore, CA 94550, USA
}

Nanosecond pulsed laser irradiation was used to fabricate colored, mechanically robust oxide "tags" on 304L stainless steel. Immersion in simulated seawater solution, salt fog exposure, and anodic polarization in a $3.5 \% \mathrm{NaCl}$ solution were employed to evaluate the environmental resistance of these oxide tags. Single layer oxides outside a narrow thickness range $(\sim 100-150 \mathrm{~nm})$ are susceptible to dissolution in chloride containing environments. The 304L substrates immediately beneath the oxides corrode severely - attributed to Cr-depletion in the melt zone during laser processing. For the first time, multilayered oxides were fabricated with pulsed laser irradiation in an effort to expand the protective thickness range while also increasing the variety of film colors attainable in this range. Layered films grown using a laser scan rate of $475 \mathrm{~mm} / \mathrm{s}$ are more resistant to both localized and general corrosion than oxides fabricated at $550 \mathrm{~mm} / \mathrm{s}$. In the absence of pre-processing to mitigate Cr-depletion, layered films can enhance environmental stability of the system.

Keywords: environmental degradation; nanosecond pulsed laser irradiation; oxide coatings; stainless steel

\footnotetext{
"Present address: Sandia National Laboratories, 7011 East Ave. Livermore, CA 94550, USA

*Please address all correspondence after publication to: dfbahr@purdue.edu; 765-494-4100
} 


\section{Introduction}

Laser-stimulated colorization of substrates has been used extensively for decorative purposes [1,2] and, recently, has been investigated for creating identifying logos, tags [3], or intrinsic labels to guard against tampering or counterfeiting [4]. A considerable amount of recent research has focused on characterizing coatings grown via pulsed laser irradiation. Cui et al. [5] successfully fabricated different oxides of chromium and manganese on AISI 304 stainless steel and characterized the effect of processing conditions on oxide morphology. Two groups have demonstrated the ability to synthesize a variety of oxide colors on 304L stainless steel [6-8], while others have shown that oxides grown on stainless steel using ultraviolet laser irradiation consist of a "duplex structure" $[9,10]$. These duplex oxides consist of a Cr-rich oxide interfacial layer, adjacent to the metal substrate, with an Fe-rich outer layer. Previous work by Adams et al. [11] identified a similar duplex phase structure for thick oxides grown during nanosecond (ns) pulsed laser irradiation of 304L stainless steel (SS 304L) with an Er-doped glass fiber laser. That study also revealed that thin oxides lack a Fe-rich outer layer, but instead are a single Cr-rich phase. Additionally, the authors emphasize that ns-pulsed laser irradiation melts the top few microns of the SS 304L substrate causing $\mathrm{Cr}$ diffusion from the substrate to the oxide leading to a Cr-denuded zone to depths slightly less than the melt-zone depth. Together these studies provide documentation of the processing-structure relationships for oxides fabricated using pulsed laser irradiation.

In a subsequent investigation, Lawrence et al. [12] reported that the topography of oxides on SS $304 \mathrm{~L}$ with thicknesses $\sim 100-500 \mathrm{~nm}$ is dominated by a series of ridges and valleys; the vertical distance from the bottom of a valley to the top of a ridge is on the order of $3 / 5$ of the total film thickness. Oxides with thicknesses greater than $\sim 100 \mathrm{~nm}$ develop a characteristic network of interconnected cracks throughout the film. These narrow channel cracks run perpendicular to the surface, are often through-thickness, and typically develop in a strained film as a means to relieve residual film stresses resulting from differences in coefficients of thermal expansion between the 
substrate and the film $[13,14]$. It is likely that residual stress increases directly with oxide thickness, as has been observed in laser-fabricated films on Ti substrates [13]; however, it is also possible that stress is constant and merely the total strain energy increases with thickness, as fracture can be an energy driven process. In either case, below an oxide thickness of $\sim 100 \mathrm{~nm}$ (corresponding to a laser scan rate of $>400 \mathrm{~mm} / \mathrm{s}$ for an average power of $5.6 \mathrm{~W}$ ) channel cracking is not observed [12]. Additionally, nanoindentation revealed that oxides on SS 304L had high hardnesses ( $>10 \mathrm{GPa})$ and resisted failure under contact loading, indicating these coatings are mechanically robust [12].

In order to be used as intrinsic labels, oxide coatings must resist environmental degradation in addition to mechanical loading and wear. Though austenitic stainless steels, such as 304L, are known for good general corrosion resistance $[15,16]$ they are susceptible to local corrosion, specifically pitting, in the presence of halide ions [17]. Recent investigations of the corrosion behavior of laser-treated stainless steels suggest that corrosion resistance depends on structure, morphology, and $\mathrm{Cr}$ concentration of the laser-treated area [18-21]. However, the environmental resistance of colored oxide tags fabricated with nanosecond pulsed laser irradiation has not been well characterized. In the current study, we investigate the stability of the oxide-stainless steel system in chloride containing environments, as marine-type environments have been identified as the most likely harsh-service condition for oxide "tags" used as authenticity markers.

Immersion testing in a simulated seawater solution and salt spray testing were selected to qualitatively capture the performance of the oxide-tagged stainless steel under marine-type conditions. Anodic polarization was employed to gain quantitative insight into the localized corrosion behavior of the oxide-substrate system in a chloride-rich environment. Degradation of the system under the exposure conditions will be interpreted in terms of previous studies of the phase, structure, deformation, and fracture of these film systems. Finally, we report on a first step towards mitigating the corrosion caused by $\mathrm{Cr}$ depletion and severe oxide channel cracking by altering the laser treatment process. Multilayered oxide films are grown by sequential irradiation of the evolving 
colored oxide layers. Working from an understanding of the effect of oxide thickness on residual stress, individual layer thicknesses are kept small, but multiple layers are grown in a single exposure area. The effect of this layering process on system corrosion resistance is investigated in terms of surface structure and morphology.

\section{Experimental}

\subsection{Oxide Films}

\subsubsection{Metallographic Preparation, Cleaning, and Imaging}

Austenitic stainless steel 304L substrates, with a composition in wt.\% of $18.11 \% \mathrm{Cr}, 8.00 \% \mathrm{Ni}$, $1.63 \% \mathrm{Mn}, 0.42 \% \mathrm{Si}, 0.14 \% \mathrm{Mo}, 0.083 \% \mathrm{~N}, 0.025 \% \mathrm{~S}$ and $\mathrm{P}, 0.023 \% \mathrm{C}$, with the balance Fe, were prepared for laser processing by metallographic grinding with 180 grit SiC paper and polishing with

9, 6, and $3 \mu \mathrm{m}$ diamond suspension. Final cleaning involved rinsing in Lenium ${ }^{\mathrm{TM}}$ degreasing solvent, followed by acetone, and then alcohol. Final substrate sample dimensions were $12.5 \mathrm{~mm} \times 12.5 \mathrm{~mm}$ $\times 3.4 \mathrm{~mm}$.

Laser-fabricated oxides were imaged optically before and after environmental exposure. After exposure, the specimens were imaged with electron microscopy using a Phillips XL-40 FESEM. Samples were then cleaned with oxalic acid to remove corrosion products and SEM was performed once again. Certain oxides were selected for post-mortem cross-sectional energy dispersive spectroscopy (EDS) to evaluate composition gradients. Using an FEI Quanta 3D Field Emission Gun Dual Beam SEM, trenches were milled in the samples with the focused ion beam (FIB). Crosssectional EDS mapping was then conducted with Oxford Instruments data collection software. 


\subsubsection{Fabrication of Single Layer Films}

Three sets of single-layer oxide coating samples were fabricated on polished stainless steel substrates following an identical laser process. An Er-doped, pulsed fiber laser from SPI Lasers was used to irradiate the polished substrates in ambient atmospheric conditions, stimulating oxide growth. Laser marking involved irradiation at focus using a pulse frequency of $225 \mathrm{kHz}$ and a pulse duration measured to be $119 \mathrm{~ns}$. The beam exiting the fiber was collimated and directed through a variable beam expander onto two Nutfield steering mirrors and then focused onto the metal surface using a Linos f163 f-theta lens. The beam was approximately Gaussian with a $1 / \mathrm{e}^{2}$ beam width equal to 59 $\mu \mathrm{m}$ at focus. A Dataray WinCamD camera and z-stage confirmed that the Rayleigh length of the beam was $>1 \mathrm{~mm}$, which is larger than the variation in working distance for leveled metal samples, indicating sufficient depth of focus to fabricate a reproducible pattern on the substrate. The relative humidity in the laboratory was $\sim 30 \%$ during laser marking. Scanning the focused laser beam over a specimen at constant speed created each oxide tag. Upon the completion of a given line, the beam was blanked and then returned to the beginning of a neighboring, adjacent line offset by $10 \mu \mathrm{m}$. This offset, referred to as hatch spacing, provides substantial beam overlap of adjacent lines and a uniform fluence within a given feature.

The specimen used for immersion testing consisted of a single SS 304L substrate with four single layer oxide patterns fabricated on the surface (henceforth quad-oxide sample); a schematic of this sample configuration is shown in Figure 1a. Average laser power and pulse frequency remained constant, while laser scan speed varied for each oxide square. Each oxide square had an area $4 \mathrm{~mm} \mathrm{x}$ $4 \mathrm{~mm}$. The second and third sample sets, designed for salt spray testing and anodic polarization, consisted of a single oxide pattern fabricated on each SS 304L substrate. 12 oxides were fabricated for salt spray testing and 6 for anodic polarization experiments. All oxides were fabricated at an average power of $5.6 \mathrm{~W}$ and a pulse frequency of $225 \mathrm{kHz}$ resulting in areas of $6 \mathrm{~mm} \times 6 \mathrm{~mm}$. Scan rates varied from 30-600 mm/s. This configuration is illustrated schematically in Figure $1 \mathrm{~b}$. 


\subsubsection{Fabrication of Multilayer Films}

Multilayered oxides were fabricated in an effort to expand the protective thickness range while also increasing the variety of film colors attainable in this range. Oxide tags were fabricated following the same basic procedure as for the single layer films; average laser power, pulse frequency, and pulse duration remained consistent with the single-layer parameters, however, only two scan speeds were employed $-475 \mathrm{~mm} / \mathrm{s}$ and $550 \mathrm{~mm} / \mathrm{s}$. Most importantly, the laser colorization process was repeated 2-12 times for a given evolving oxide tag, at a specified scan rate, in order to develop a layered structure.

\subsubsection{Summary of Film Thicknesses}

Thicknesses of single layer films were directly measured with TEM on FIB cross-sections and have been reported previously by Adams et al. [11], as a function of laser scan rate. For convenience, these measurements have been collected in Table I.

Thicknesses of multilayer films were not directly measured, but were estimated based on values reported in Table I. The primary objective of the layering process was to fabricate films with total thicknesses of $75 \mathrm{~nm}, 100 \mathrm{~nm}, 125 \mathrm{~nm}, 200 \mathrm{~nm}$, and $300 \mathrm{~nm}$ using individual layer thicknesses (period thickness) of $50 \mathrm{~nm}$ or less.

From Table I, the thickness of a single layer film grown at a laser scan rate of $475 \mathrm{~mm} / \mathrm{s}$ is estimated to be $50 \mathrm{~nm}$. Thus, at $475 \mathrm{~mm} / \mathrm{s}$, multilayered oxides with total thicknesses of $100 \mathrm{~nm}, 200$ $\mathrm{nm}$, and $300 \mathrm{~nm}$ were developed by iterative irradiation of the same $6 \mathrm{~mm} \times 6 \mathrm{~mm}$ area, creating films of 2 layers, 4 layers, and 6 layers, respectively.

Similarly, a single-layer oxide film fabricated at $550 \mathrm{~mm} / \mathrm{s}$ is approximately $25 \mathrm{~nm}$ thick. At this scan rate, films with total thicknesses of $75 \mathrm{~nm}, 125 \mathrm{~nm}$, and $300 \mathrm{~nm}$ were achieved by iteratively irradiating the same area to build layered films consisting of 3 layers, 5 layers, and 12 layers. 
Duplicates of each sample were created for parallel environmental testing paths: anodic polarization and salt spray testing.

\subsection{Environmental Degradation Test Procedures}

Immersion testing was conducted by submerging the quad-oxide sample (single layer coatings) in a simulated seawater solution ( $\mathrm{pH} \mathrm{6)}$ per the ASTM G31 standard [22] for 25 days. The exposed SS 304L substrate around the marked regions was enameled to ensure that only the laser modified oxide surfaces were exposed to the environment. At the conclusion of the exposure period, the sample was removed, rinsed with deionized water, and dried for 24 hours prior to microscopy.

Salt spray testing was conducted on the 12 individual single layer oxide samples as well as the on the 6 multilayered coatings. A polished blank SS 304L specimen was included in the test matrix as a control sample. All stainless steel substrates were enameled to ensure that only oxide areas were exposed to the salt fog environment. Salt spray exposure was performed in accordance with the ASTM B117 standard [23] for 168 hours. Samples were rinsed with deionized water and dried for at least 24 hours prior to microscopy.

The last environmental test to which the oxides were subjected was anodic polarization. An untreated stainless steel blank and single layer oxides fabricated at $30 \mathrm{~mm} / \mathrm{s}, 300 \mathrm{~mm} / \mathrm{s}, 350 \mathrm{~mm} / \mathrm{s}$, and $500 \mathrm{~mm} / \mathrm{s}$ were anodically polarized to evaluate the pitting corrosion resistance and general localized corrosion behavior of the single layer oxide-substrate system. These oxides were selected as a representative subset of the oxides exposed to salt spray testing. Additionally, all six multilayered films were subjected to polarization testing. Anodic polarization tests were performed with a conventional three-electrode cell, with a $\mathrm{Pt}$ counter electrode and a $\mathrm{Ag} / \mathrm{AgCl}$ reference electrode, using a Gamry DC105 corrosion test system. Polarization curves were produced in a 3.5\% $\mathrm{NaCl}$ solution at a sweep rate of $0.5 \mathrm{mV} / \mathrm{s}$ after stabilization of the open circuit potential. 


\section{Results}

\subsection{Immersion Testing}

After 25 days exposure to simulated seawater, a thick corrosion product covered all oxide areas. Optical micrographs obtained before and after exposure are presented in Figure 2. The corrosion product deposited on top of the laser-oxide areas; the laser-fabricated oxide is clearly visible in the SEM image of a post-exposure FIB cross-section (Figure 3a). The corrosion product was not welladhered to the oxide tag, flaking off easily when imaged with a high energy electron beam or after cleaning with oxalic acid, revealing the laser-fabricated oxide still present on the metal surface. These results suggest that the corrosion product develops primarily from corrosion of the underlying steel substrate, rather than severe dissolution of single layer oxide coatings.

Subsequent post-mortem cross-sectional EDS of the corroded samples enables qualitative assessment of composition as a function of depth. EDS mapping (Figure 3a) detects a difference in $\mathrm{Cr}, \mathrm{Fe}$, and $\mathrm{O}$ content throughout the substrate and into the laser-oxide and corrosion product. Linear point profiling (Figure 3b) of an as-received oxide mounted in cross-section confirms EDS mapping and shows a decreasing $\mathrm{Cr}$ concentration moving from the bulk substrate towards the oxide interface. The results are in agreement with previous STEM EDS work by Adams et al. [11], which revealed that $\mathrm{Cr}$ is depleted from the substrate to a maximum depth of $\sim 2 \mu \mathrm{m}$ for the case of a $5.6 \mathrm{~W}, 225 \mathrm{kHz}$ oxide (depletion depth varies with oxide thickness). Stainless steel derives its corrosion resistance from the formation of a continuous $\mathrm{Cr}_{2} \mathrm{O}_{3}$ layer when $\mathrm{Cr}$ is dispersed throughout the matrix at a concentration of greater than approximately $12 \%$, therefore, depletion of solute $\mathrm{Cr}$ below this critical concentration leads to decreased corrosion resistance $[24,25]$. The deposition of a corrosion product on top of the laser-oxides suggests that enough $\mathrm{Cr}$ is depleted from the substrate melt-zone during laser processing to reduce the near-surface $\mathrm{Cr}$ concentration below $\sim 12 \mathrm{wt}$ \%, making the SS 304L susceptible to chloride attack [26]. 


\subsection{Salt Spray Testing}

Salt spray testing was conducted on 12 single layer oxides in order to verify the proposition that laser processing parameters, and thus film thickness, directly impact the corrosion resistance of a particular oxide-substrate system. A qualitative assessment of the severity of corrosion, based on the extent of the corrosion product, as a function of oxide thickness suggests that systems composed of thick oxides $(>200 \mathrm{~nm})$ as well as thin oxides $(<80 \mathrm{~nm})$ are susceptible to chloride attack while oxides on the order of 100-150 nm thick are protective. Micrographs for six of the 12 oxides exposed to salt fog are presented in Figure 4; for comparison, a micrograph of the exposed uncoated SS 304L blank is included.

Post-mortem electron microscopy of oxide surfaces after salt spray exposure and subsequent oxalic acid cleaning to remove excess corrosion product reveal the development of pits at triple points or other crack junctions, as shown in Figure 5a and 5b, and widening of surface channel cracks that form during laser processing, as in Figure 5c. In some cases, removal of the thick corrosion product reveals oxide degradation, but not complete dissolution, in the vicinity of widened cracks or pits, as in Figure 5c, indicating that channel cracks are weak points in the film where both substrate corrosion and oxide dissolution can proceed.

Similarly, salt spray testing of multilayered coatings results in corrosion product deposition on the surface of all oxides, as shown in Figure 6a-d. The most pervasive corrosion product developed on the surface of the 5-layer and 12-layer oxides. The deposition of a corrosion product indicates that the oxides are not impervious to chloride containing solutions and the substrate melt zone is likely still depleted of $\mathrm{Cr}$ after laser processing, even for the thinnest films. However, comparing Figure 6a-d with Figure 4 it is evident that multilayered films are, in general, more resistant to environmental degradation than single layer films.

Furthermore, upon inspection of Figure 6e-h, it is clear that the laser-fabricated oxide is still intact after the corrosion product has been removed from the surface, although the surface 
appearance is changed due to degradation. The samples were cleaned with a natural source of oxalic acid. This process removed the rust-like corrosion product deposited on top of the oxides, but leaves the oxides intact. In some cases the oxide surface is discolored where the corrosion product had previously adhered to the surface; compare, for example, Figure $6 \mathrm{~b}$ and $6 \mathrm{f}$. These observations indicate while the oxides are not impenetrable for chloride ions, which can result in substrate corrosion, the coatings do resist dissolution to varying degrees. The 3-layer film is the only coating that does not appear to have suffered any film dissolution after exposure. Additionally, closer inspection of the oxides with electron microscopy show similar behavior to that seen in the single layer films - namely that channel cracks are the likely points of ingress for corrosive ions, which can cause crack widening, pit development, and some oxide dissolution, in addition to substrate corrosion. Figure 7 presents electron micrographs of oxides cleaned after salt spray exposure; the 3layer film shows no discernible surface dissolution but channel cracks are visible, while surface degradation is obvious for the 12-layer film. In contrast with the single layer films, all the multilayered oxide films manifest channel cracking. Though the residual stresses in these films have not been investigated, the presence of cracks seems to contribute to film degradation and substrate corrosion.

\subsection{Potentiodynamic Testing}

Representative anodic polarization curves for the single layer coatings are presented in Figure 8a; for clarity only curves for the untreated SS 304L, the 489-nm thick oxide, and the 40-nm thick oxide are shown. The corrosion potentials for all five samples are plotted as a function of film thickness in Figure 8b.

Anodic polarization of untreated SS 304L results in pitting of the SS 304L, which effectively begins at $0 \mathrm{~V}$ vs $\mathrm{Ag} / \mathrm{AgCl}$. Anodic current densities $\left(i_{\text {anodic }}\right)$ at the highest polarization potentials are large and limited by concentration polarization phenomena. This behavior is typical of a passive 
metal subjected to pitting corrosion [27] and expected for stainless steel, which is known to be susceptible to pitting at low potentials in chloride-containing solutions. Anodic polarization also causes pitting and dissolution of the oxide coating and localized corrosion of the substrate. Oxides with thickness of $147 \mathrm{~nm}, 100 \mathrm{~nm}$, and $40 \mathrm{~nm}$ have anodic current densities slightly lower than those of the untreated SS 304L and corrosion potentials $\left(E_{\text {corr }}\right)$ cathodic to the untreated substrate, indicating the oxide-substrate systems are more susceptible to localized corrosion. In fact, corrosion potential appears to vary directly with oxide thickness; thicker oxides are the most susceptible to localized corrosion. The $489 \mathrm{~nm}$ oxide shows no passivation behavior at all, but instead begins to dissolve immediately after the corrosion potential is reached. The corrosion potential for this oxide shifts to a more cathodic value than that of the thinner oxides, reflecting a higher corrosion rate, consistent with salt spray test results. Figure 9 compares optical micrographs of these oxide areas before and after anodic polarization and shows the degree of local corrosion observed for the oxides and untreated SS 304L.

Multilayer oxide coatings were also subjected to anodic polarization. Oxides grown at both 475 $\mathrm{mm} / \mathrm{s}$ and $550 \mathrm{~mm} / \mathrm{s}$ show no improvement in localized corrosion resistance compared with the untreated 304L stainless steel control sample, as the corrosion potentials for all laser-treated samples are more cathodic than the virgin SS 304L. These values are plotted as a function of total number of layers in the coating and total oxide coating thickness in Figure 10a-b. Additionally, all laser treated samples show an increase in anodic current densities compared with the untreated material and are concentration polarization limited at large polarization potentials. Current densities are plotted in Figure 10c-d. Evaluating the oxides fabricated at $550 \mathrm{~mm} / \mathrm{s}$ reveals that the corrosion potentials are cathodic to the untreated steel and generally more negative than the $475 \mathrm{~mm} / \mathrm{s}$ oxides (Figure 10a-b). Additionally, breakdown potentials for the 3-layer and 5-layer films are more noble than the virgin SS 304L. In contrast, the 12-layer film shows only active behavior. Anodic current densities, plotted in Figure 8c-d, are concentration polarization limited. Oxides grown at $475 \mathrm{~mm} / \mathrm{s}$ behave similarly; 
the breakdown potentials for the 4-layer film and the 2-layer film are greater than the 6-layer film and the untreated SS 304L. $E_{\text {corr }}$ tends to decrease as a function of the number of layers and total film thickness for the $475-\mathrm{mm} / \mathrm{s}$ oxides, but no clear trend is evident for the $550-\mathrm{mm} / \mathrm{s}$ oxides. The large value observed for the 12-layer film may be an outlier, but we cannot state this with certainty in the absence of compelling statistics. Comparing $i_{\text {anodic }}$ as a function of number of layers does not expose a clear trend. However, when evaluated as a function of coating thickness, two groups are discernible. Oxides with thicknesses $75 \mathrm{~nm}$ to $125 \mathrm{~nm}$ have $i_{\text {anodic }}$ values greater than $0.2 \mathrm{~A} / \mathrm{cm}^{2}$, while $200-\mathrm{nm}$ to $300-\mathrm{nm}$ thick films have values less than $0.15 \mathrm{~A} / \mathrm{cm}^{2}$. In general, polarization data suggests oxides fabricated at $475 \mathrm{~mm} / \mathrm{s}$ are more resistant to localized corrosion than oxides grown at $550 \mathrm{~mm} / \mathrm{s}$ due to a smaller cathodic shift in corrosion potentials.

Representative optical micrographs of the multilayered oxide films before and after anodic polarization, shown in Figure 11, confirm the electrochemical data. In general, oxide degradation is more severe for oxides grown at $550 \mathrm{~mm} / \mathrm{s}$. The pits formed are larger and/or more prolific for the $475 \mathrm{~mm} / \mathrm{s}$ films. Pitting is more severe for oxides with 3 and 5 layers than for the 12-layer film. Pit morphology is impacted by exposure direction - samples were suspended vertically, thus pits are elongated. Fewer pits are observed for oxides grown at $475 \mathrm{~mm} / \mathrm{s}$; those that are observed are less severe than the pits that develop in the $550 \mathrm{~mm} / \mathrm{s}$ oxides.

\section{Discussion}

The observed extensive corrosion of the laser-modified stainless steel system supports previous assertions that single layer oxides fabricated on SS 304L via certain laser irradiation parameters are non-protective. Heterogeneities, such as cracks formed as a means to relax residual tensile stress in the oxide films, hinder the ability of the oxide to function as a barrier for the underlying substrate metal. Because all visible substrate is enameled prior to immersion or salt spray testing, the preexisting surface cracks that pervade the oxide area provide the only path for exposure of the stainless 
steel substrate to the aggressive environment. It is likely that the Cr-denuded zone generated during oxide fabrication results in a substrate more susceptible to chloride attack and the channel cracks found in the oxide allow the electrolyte to penetrate the oxide, exposing the Cr-depleted substrate. As described in a previous publication [12], the degree of oxide channel cracking depends on coating thickness, thus it is likely that susceptibility to corrosive attack also depends on oxide thickness and Cr-depletion depth in the substrate. Similar observations have been recorded by Pacquentin et al. [18] for SS 304L modified with laser surface melting (LSM) using a ytterbium-doped nanosecond pulsed laser. The authors note that when LSM results in the growth of an oxide with a thickness on the order of $300 \mathrm{~nm}$, the film is mudflat cracked and a chromium depletion zone exists immediately beneath the oxide. Passive behavior disappears and the pitting potential of this sample becomes more negative than for untreated samples or those with oxide coatings on the order of $100 \mathrm{~nm}$.

Integrating the current salt spray and anodic polarization study with a previous fracture behavior investigation by Lawrence et al. [12] provides insight into the coupling of laser-oxide structure with environmental resistance. Single layer oxides with thicknesses greater than $\sim 150 \mathrm{~nm}$ suffer from pervasive channel cracking. Through-thickness cracks provide a path for exposure of the substrate immediately beneath the oxide to the aggressive environment and act as "weak spots" in the coating that are more easily degraded than a homogenous surface. Additionally, the Cr-depleted SS 304L substrate is susceptible to chloride attack and thus a thick corrosion product deposits on top of the exposed area. Electron microscopy of oxide surfaces after salt spray exposure and subsequent cleaning to remove excess corrosion product reveal the development of pits at triple points or other crack junctions, as shown in Figure 5a and 5b, and widening of surface channel cracks as in Figure 5c. These post-mortem observations seem to support through-thickness cracks as the likely ingress path for chloride ions. In some cases, removal of the thick corrosion product reveals oxide degradation, but not complete dissolution, in the vicinity of widened cracks or pits, as in Figure 5c, indicating that channel cracks are weak points in the film where both substrate corrosion and oxide 
dissolution can proceed. Though we cannot determine with certainty the order of degradation processes, in general we propose the following mechanism: (1) pits develop at channel crack junctions, (2) pits grow and cracks widen with continued exposure, (3) surface dissolution proceeds as additional pits form and cracks widen, (4) substrate corrosion likely accompanies (3) and causes deposition of a corrosion product on top of the laser-fabricated oxide tag. Schematics of these degradation processes are shown in Figure 5d and 5e. Anodic polarization data appears to substantiate the proposed mechanism. However, for the shorter exposure times utilized during electrochemical testing, general dissolution of the oxide surface is not observed. Rather, growing pits may give way to local spallation of the oxide. Additionally, no corrosion product deposits on top of the laser-oxide, though corrosion product settles along the bottom of the electrochemical cell. This corrosion product may be the result of both oxide dissolution as well as substrate corrosion.

Other investigators have also correlated the corrosion susceptibility of coated steels to coating thickness [28] and to residual film stresses and degree of film cracking [29]. Chou et al. [28] found that salt spray testing led to increased corrosion rates for TiN-coated 304L below a critical thickness, while Shieu et al. [29] determined that the propensity for film cracking increases with residual film stress, which leads to increased corrosion rates in $\mathrm{NaCl}$ environments. In the current study, single layer oxides with thicknesses less than $\sim 100 \mathrm{~nm}$ do not suffer extensive channel cracking, suggesting the films are thin enough to avoid significant residual stresses and thus deform in union with the stainless steel substrate. Such thin oxides, with a likely composition of $\mathrm{MnCr}_{2} \mathrm{O}_{4},[11]$ are susceptible to degradation in a chloride-rich environment and so do not serve as a protective barrier preventing corrosion of the Cr-depleted substrate. High point or line defect densities may also contribute to poor corrosion resistance; defects can act as "short circuit" diffusion paths for the aggressive species. A previous investigation [12] of electrical properties of these films suggested that oxides fabricated at fast laser scan rates, which results in very thin films, have both a lower electrical resistivity and resistance than thicker films. In contrast with fracture behavior, film conductance 
does not depend on oxide thickness; rather, increasing defect density (which corresponds to increasing charge carrier concentration) is identified as the cause. Other investigations have linked the electrical and chemical properties of passive films and thermally grown oxides on stainless steel [30-34]. Guo et al. [31] found that that the electrical conductivity of passive films on a duplex stainless steel varies as a function of film thickness and composition; films less than $5 \mathrm{~nm}$ thick are p-type semiconductors and have a higher $\mathrm{Cr}$ :Fe ratio than $5 \mathrm{~nm}$ thick films, which are n-type semiconductors. Hakiki et al. [30] notes that the electronic structure of relatively thick thermally grown oxides (TGO) on 304 stainless steel is similar to that found for thin passive films. The TGO films are dual phase, with a Cr- and Fe-rich inner layer and Fe-rich outer layer, with different conductivities (both are semiconductors). The authors found that both TGO and passive films reveal similar capacitance despite different thicknesses and donor densities, similar to the results of the current study. In the current investigation, thin oxides are fabricated at very fast laser scan rates and are suspected to contain a larger defect density than oxides fabricated at slower laser scan rates. Defects, acting as charge carriers, may also enhance diffusion of the aggressive species to the Crdepleted substrate [35], increasing the likelihood of corrosion. Thus, it is specific processing parameters that affect the defect structure in the oxide, leading to poor corrosion resistance, rather than the thickness of the oxide films.

Single layer oxides with thicknesses of $\sim 100-150 \mathrm{~nm}$ are protective. These coatings, with a single-phase Cr-rich composition containing some Mn and Fe, have thicknesses below the critical point for extensive through-thickness channel cracking. They are continuous, well-adhered coatings, likely with a relatively low defect density. Thus, in the absence of any pre- or post-processing to avoid the development of a Cr-denuded zone in SS 304L substrates, protective single layer oxide coatings can be fabricated using laser processing conditions which result in coating thicknesses of $100-150 \mathrm{~nm}$. 
Initial environmental testing of multilayered oxide films suggests that even though individual layer thickness is kept small, $\mathrm{Cr}$ is still depleted from the substrate melt zone. In the absence of any substrate pre-processing to mitigate $\mathrm{Cr}$ depletion, layered coatings appear to have only marginally superior environmental stability when compared with single layer films. However, additional investigations need to be conducted to understand the contributions of residual stresses and accumulated heat-input on oxide film behavior during environmental exposure.

\section{Summary}

Corrosion resistance of a novel oxide-substrate system fabricated via single-pass or multi-pass nanosecond pulsed laser irradiation of SS 304L substrates in chloride containing environments, similar to marine conditions, has been investigated through immersion testing, salt spray exposure, and anodic polarization in $\mathrm{NaCl}$ solution. Environmental exposure results are interpreted in terms of previous investigations of oxide structure and fracture behavior.

1. Laser grown oxides on SS 304L with thicknesses greater than $200 \mathrm{~nm}$ are generally nonprotective in chloride-containing environments, likely due to the presence of throughthickness cracks, allowing exposure of the Cr-depleted substrate to the aggressive environment. High temperature laser processing leaves a $\mathrm{Cr}$-denuded zone in the substrate that extends to about half of the melt zone depth; this Cr-depleted substrate microstructure is susceptible to corrosion in chloride environments, thus a corrosion product deposits atop the exposed laser-formed oxide areas.

2. Single layer oxides on SS 304L with thicknesses less than $\sim 100 \mathrm{~nm}$ are single-phase and do not contain through-thickness cracks, but do not prevent corrosion of the Cr-depleted stainless steel substrates. These films likely have high defect densities that may act as short circuit diffusion paths for the aggressive species, enabling corrosion of the $\mathrm{Cr}$-depleted 
substrate.

3. Oxide coatings that have thicknesses in the range of $\sim 100-150 \mathrm{~nm}$ are protective in aggressive chloride environments. Oxides in this thickness range are single-phase and not mudflat-cracked and as such are resistant to atmospheric chloride attack, but still susceptible to localized electrochemical corrosion.

4. In an effort to tailor laser processing to mitigate the corrosion caused by $\mathrm{Cr}$ depletion in the melt zone generated by laser heat input, novel multilayered oxides were fabricated on SS 304L. Individual layer thicknesses were kept small, but total layer thickness encompassed the range of thicknesses generated previously for single layer films. Layered films grown using a laser scan rate of $475 \mathrm{~mm} / \mathrm{s}$ tend to be more resistant to both localized and general corrosion than oxides fabricated with a scan rate of $550 \mathrm{~mm} / \mathrm{s}$.

5. Though the Cr-depleted substrates are still susceptible to corrosion in a chloride-containing environment, any corrosion product that deposits on the surface of the oxides can be removed by cleaning with oxalic acid. Importantly, the laser-fabricated oxide is still present on the surface after salt spray exposure and cleaning, suggesting that the oxide is relatively stable in harsh conditions.

Nanosecond pulsed laser irradiation can be successfully employed to fabricate multilayered oxide coatings which are both mechanically robust and resist environmental degradation.

\section{Acknowledgement}

This work was supported by the Stewardship Science Graduate Fellowship Program under grant number DE-NA0002135 (to SKL) and the Defense Threat Reduction Agency, Basic Research Award \# IACRO 13-5897I, to Purdue University sub-contracted through Sandia National Laboratories. Sandia National Laboratories is a multiprogram laboratory managed and operated by Sandia Corporation, a wholly owned subsidiary of Lockheed Martin Company, for the U.S. 
Department of Energy's National Nuclear Security Administration under contract DE-AC04-

94AL85000. The authors would like to thank V.C. Hodges and D. Saiz of Sandia National Labs for help with sample preparation and Dr. D. Enos at Sandia National Labs for the opportunity to use equipment in the corrosion test facilities and for enlightening discussion. 


\section{References:}

[1] A.M. Carey, W.M. Steen, D. Watkins, Laser Surface Ornamentation, in: Proc. Int. Congr. Appl. Lasers Electro-Optics ICALEO, 1998: p. D170.

[2] H.Y. Zheng, D. Rosseinsky, G.C. Lim, Laser-evoked coloration in polymers, Appl. Surf. Sci. 245 (2005) 191-195.

[3] H.Y. Zheng, X.C. Wang, G.C. Lim, J.L. Tan, A process study for laser-induced surface coloration, J. Laser Appl. 14 (2002) 215-220.

[4] D.P. Adams, J. McDonald, B.H. Jared, V.C. Hodges, D. Hirschfeld, D.S. Blair, et al., Method of Intrinsic Marking, U.S. Patent 13/403117, 2014.

[5] C. Cui, J. Hu, Y. Liu, K. Gao, Z. Guo, Morphological and structural characterizations of different oxides formed on the stainless steel by Nd:YAG pulsed laser irradiation, Appl. Surf. Sci. 254 (2008) 6537-6542.

[6] V.P. Laakso, S. Ruotsalainen, H. Leinonen, A. Helle, R. Penttilä, A. Lehmuskero, J. Hiltunen, DIME Project Report, VTT Research Center Report VTT-R-02403-09, VTT, Lappeenranta, Finland. (2009) p. 65.

[7] A.P. Laakso, H. Pantsar, H. Leinonen, A. Helle, Preliminary study on corrosion and wear properties of laser color marked stainless steel, in: Proc. Int. Congr. Appl. Lasers and ElectroOptics, ICALEO (2008) p. 212-221.

[8] Z. Hongyu, Laser-induced colours on metal surfaces, SIMTech Technical Report PT/01/004/AM (2001).

[9] Z.L. Li, H.Y. Zheng, K.M. Teh, Y.C. Liu, G.C. Lim, H.L. Seng, et al., Analysis of oxide formation induced by UV laser coloration of stainless steel, Appl. Surf. Sci. 256 (2009) 15821588 .

[10] H.Y. Zheng, G.C. Lim, Process for laser marking metal, U.S. Patent 09/799724, 2003.

[11] D.P. Adams, V.C. Hodges, D.A. Hirschfeld, M.A. Rodriguez, J.P. Mcdonald, P.G. Kotula, Nanosecond pulsed laser irradiation of stainless steel 304L : Oxide growth and effects on underlying metal, Surf. Coatings Technol. 222 (2013) 1-8.

[12] S.K. Lawrence, D.P. Adams, D.F. Bahr, N.R. Moody, Mechanical and electromechanical behavior of oxide coatings grown on stainless steel 304L by nanosecond pulsed laser irradiation, Surf. Coatings Technol. 235 (2013) 860-866.

[13] S.K. Lawrence, D.P. Adams, D.F. Bahr, N.R. Moody, Deformation and fracture of a mudflat cracked laser-fabricated oxide on Ti, J. Mater. Sci. 48 (2013) 4050-4058.

[14] J.W. Hutchinson, Z. Suo, Mixed Mode Cracking in Layered Materials, Adv. Appl. Mech. 29 (1992) 63-191. 
[15] A.A. Hermas, K. Ogura, Effects of Alloying Additions on the Spontaneous Passivation of Stainless Steels Containing Copper at Different Temperatures, Electrochim. Acta. 41 (1996) 1601-1609.

[16] S. Haupt, H.-H. Strehblow, A Combined Surface Analytical and Electrochemical Study of the Formation of Passive Layers on Fe/Cr Alloys in 0.5 M H2SO4, Corros. Sci. 37 (1995) 43-54.

[17] M.A.M. Ibrahim, S.S. Abd El Rehim, M.M. Hamza, Corrosion behavior of some austenitic stainless steels in chloride environments, Mater. Chem. Phys. 115 (2009) 80-85.

[18] W. Pacquentin, N. Caron, R. Oltra, Nanosecond laser surface modification of AISI 304L stainless steel: Influence the beam overlap on pitting corrosion resistance, Appl. Surf. Sci. 288 (2014) 34-39.

[19] A. Conde, I. García, J.J. de Damborenea, Pitting corrosion of 304 stainless steel after laser surface melting in argon and nitrogen atmospheres, Corros. Sci. 43 (2001) 817-828.

[20] I.Y. Khalfallah, M.N. Rahoma, J.H. Abboud, K.Y. Benyounis, Microstructure and corrosion behavior of austenitic stainless steel treated with laser, Opt. Laser Technol. 43 (2011) 806813.

[21] A.J. Antończak, D. Kocoń, M. Nowak, P. Kozioł, K.M. Abramski, Laser-induced colour marking —-Sensitivity scaling for a stainless steel, Appl. Surf. Sci. 264 (2013) 229-236.

[22] Standard Guide for Laboratory Immersion Corrosion Testing of Metals, NACE TM0169/ASTM G31, 2012.

[23] Standard Practice for Operating Salt Spray ( Fog ) Apparatus, ASTM B117, 2011.

[24] H.S. Khatak, B. Raj, Corrosion of Austenitic Stainless Steels: Mechanism, Mitigation, and Monitoring, Woodhead, Materials Park, OH, 2002.

[25] J.R. Davis, Stainless Steels, ASM International, Materials Park, OH, 1994.

[26] R.V. Trax, J.C. Holzwarth, Effect of Chromium Depleted Surface on Corrosion Behavior of Type 430 Stainless Steel, Corrosion. 16 (1960) 271t-274t.

[27] A. Fossati, F. Borgioli, E. Galvanetto, T. Bacci, Corrosion resistance properties of glowdischarge nitrided AISI 316L austenitic stainless steel in $\mathrm{NaCl}$ solutions, Corros. Sci. 48 (2006) 1513-1527.

[28] W.-J. Chou, G.-P. Yu, J.-H. Huang, Corrosion behavior of TiN-coated 304 stainless steel, Corros. Sci. 43 (2001) 2023-2035.

[29] F.S. Shieu, Y.C. Sung, L.H. Cheng, J.H. Huang, G.P. Yu, Control Of The Corrosion Resistance of TiN-coated AISI 304 Stainless Steel, Corros. Sci. 39 (1997) 893-899.

[30] N.E. Hakiki, M.F. Montemor, M.G.S. Ferreira, M.C. Belo, Semiconducting properties of thermally grown oxide films on AISI 304 stainless steel, Corros. Sci. 42 (2000) 687-702. 
[31] L.Q. Guo, M.C. Lin, L.J. Qiao, A.A. Volinsky, Duplex stainless steel passive film electrical properties studied by in situ current sensing atomic force microscopy, Corros. Sci. 78 (2014) $55-62$.

[32] S. Mischler, A. Vogel, H.J. Mathieu, D. Landolt, The Chemical Composition of the Passive Film on Fe-24Cr and Fe-24Cr-11Mo Studied by AES , XPS and SIMS, Corros. Sci. 32 (1990) 925-944.

[33] M.F. Montemor, M.G.S. Ferreira, N.E. Hakiki, M. Da Cunha Belo, Chemical composition and electronic structure of the oxide films formed on 316L stainless steel and nickel based alloys in high temperature aqueous environments, Corros. Sci. 42 (2000) 1635-1650.

[34] M.G.S. Ferreira, N.E. Hakiki, G. Goodlet, S. Faty, A.M.P. Simoes, M. Da Cunha Belo, Influence of the temperature of film formation on the electronic structure of oxide films formed on 304 stainless steel, Electrochim. Acta. 46 (2001) 3767-3776.

[35] J.J. Noel, B.M. Ikeda, N.H. Miller, S.R. Ryan, D.W. Shoesmith, S. Sunder, et al., Passive oxide films on titanium in aqueous chloride solution probed by electrochemistry, XPS and in situ neutron reflectometry, in: J.A. Bardwell (Ed.), Proc. Symp. Surf. Oxide Film., Electrochemical Society, Inc., San Antonio, 1996: pp. 246-257. 


\section{TABLES}

Table I. Processing conditions and resulting film thicknesses for two sets of oxide samples. All oxides fabricated at an average laser power of $5.6 \mathrm{~W}$. All salt spray samples manufactured at a laser pulse frequency of $225 \mathrm{kHz}$.

\begin{tabular}{cccc}
\hline \multicolumn{2}{c}{ Immersion Test Samples } & \multicolumn{2}{c}{ Salt Spray Test Samples } \\
\hline Laser Scan Rate & Thickness & Laser Scan Rate & Thickness \\
$(\mathrm{mm} / \mathrm{s})$ & $(\mathrm{nm})$ & $(\mathrm{mm} / \mathrm{s})$ & $(\mathrm{nm})$ \\
30 & 489 & 30 & 489 \\
47 & 405 & 47 & 405 \\
80 & 403 & 80 & 403 \\
175 & 302 & 175 & 302 \\
& & 200 & 285 \\
& & 225 & 196 \\
& & 250 & 150 \\
& & 300 & 147 \\
& & 350 & 100 \\
& 400 & 84 \\
& 450 & 65 \\
& & 500 & 40 \\
\hline
\end{tabular}




\section{FIGURES}

Figure 1. Schematic illustration of laser-fabricated oxide samples showing quad-oxide configuration for immersion testing (a) and single oxide configuration for salt spray exposure and anodic polarization (b).

Figure 2. Quad-oxide samples before (left) and after (right) immersion in simulated seawater solution for 25 days. Uniform corrosion product suggests oxides are non-protective, likely due to the presence of through-thickness cracks, allowing exposure of $\mathrm{Cr}$-depleted substrate to chloride containing environment.

Figure 3. Electron micrograph showing FIB cut cross-section through corrosion product, oxide, and substrate, with resulting EDS maps of the red boxed region shown to the right. Regions between white dotted lines indicate the laser-fabricated oxide (a). Linear EDS point profiles of a metallographic cross-section of an as-fabricated oxide (b). EDS data indicates substrate melt zone is depleted of $\mathrm{Cr}$ immediately beneath the oxide (c).

Figure 4. Optical micrographs of six oxides subjected to 168 hours of salt spray exposure indicate severity of substrate corrosion correlates with oxide thickness and degree of though-thickness channel cracking.

Figure 5. Electron micrograph of two pits in a $175 \mathrm{~mm} / \mathrm{s}$ oxide (a). Apparent horizontal lines on the surface reflect the laser scan direction. Pits form at the intersection of channel cracks, as shown in (b). A schematic of this process is shown in (d). Salt spray exposure also causes widening of channel cracks and subsequent "flaking-off" of the oxide as evident in the SEM 
image in (c) and accompanying schematic (e). Cross-sections shown below plan-view schematics in (c) and (e) are taken along dashed lines.

Figure 6. Optical micrographs layered oxides fabricated at $475 \mathrm{~mm} / \mathrm{s}$ and $550 \mathrm{~mm} / \mathrm{s}$ after 168 hours of salt fog exposure (a-d) and after removing the corrosion product with oxalic acid cleaning (e-h).

Figure 7. Electron micrographs of a 3-layer oxide (a,c) and a 12-layer oxide (b,d) after salt fog exposure and subsequent oxalic acid cleaning. Zoomed-in views of white boxed areas are shown in (c) and (d). No surface degradation is apparent for the 3-layer film, conversely, the 12-layer coating shows severe oxide dissolution; surface channel cracks are still apparent, as shown in (c).

Figure 8. Anodic polarization curves (a) of an untreated SS 304L sample, as well as two laserfabricated oxide samples, a subset of the samples subjected to salt spray testing. Corrosion potential values from polarization curve vary directly with film thickness (b).

Figure 9. Optical micrographs of samples subjected to anodic polarization. Images (a-e) show sample surfaces prior to polarization, images $(\mathrm{d}-\mathrm{j})$ show degradation of surface after anodic polarization.

Figure 10 . Corrosion potential $\left(E_{\text {corr }}\right)$ and anodic current density $\left(i_{\text {anodic }}\right)$ values taken from anodic polarization curves plotted as a function of the number of layers in each film $(a, c)$ and as a function of the film thickness $(b, d)$. Film thickness is estimated by multiplying the thickness of a single oxide by the number of layers in each film. 
Figure 11. Optical micrographs of $475 \mathrm{~mm} / \mathrm{s}$ and $550 \mathrm{~mm} / \mathrm{s}$ layered oxides before (a-d) and after (e-h) anodic polarization in $3.5 \% \mathrm{NaCl}$ solution. 
(a) SS 304L Substrate

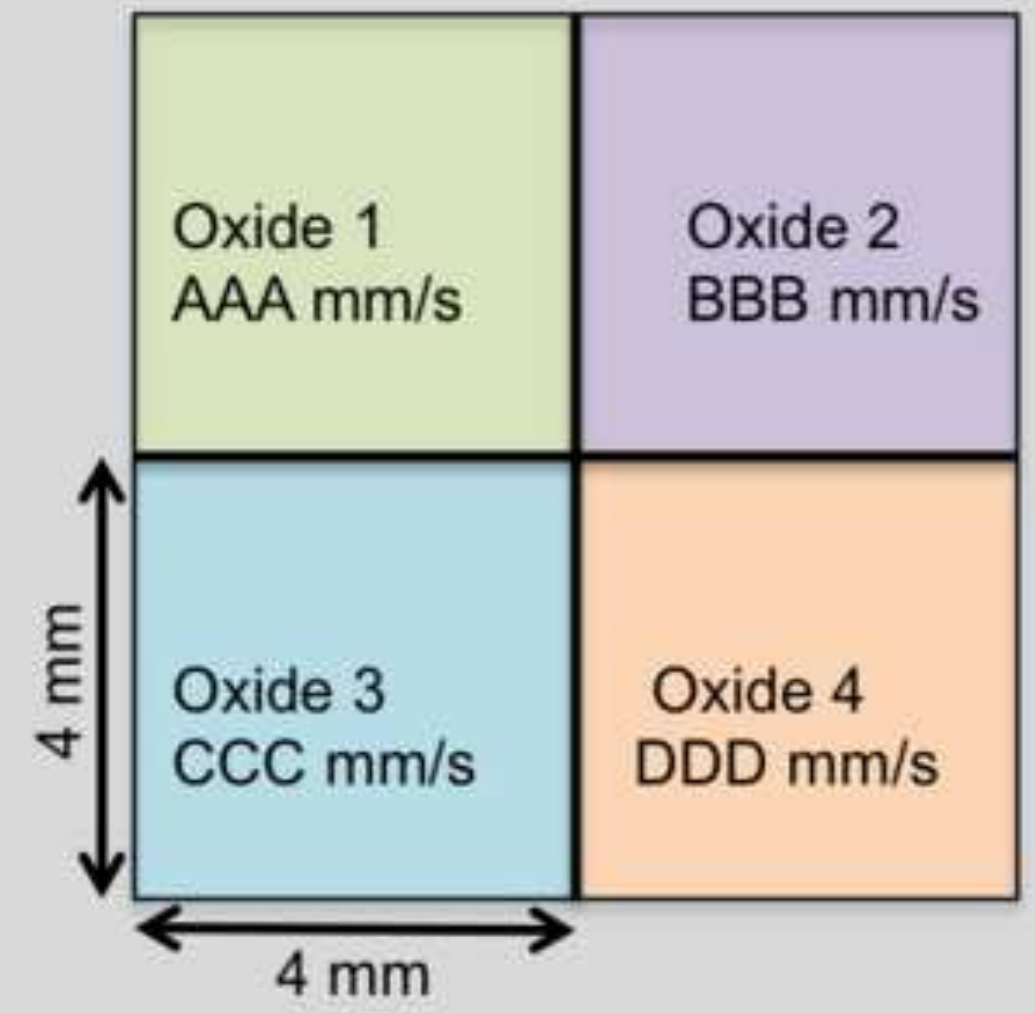

(b) SS 304L Substrate

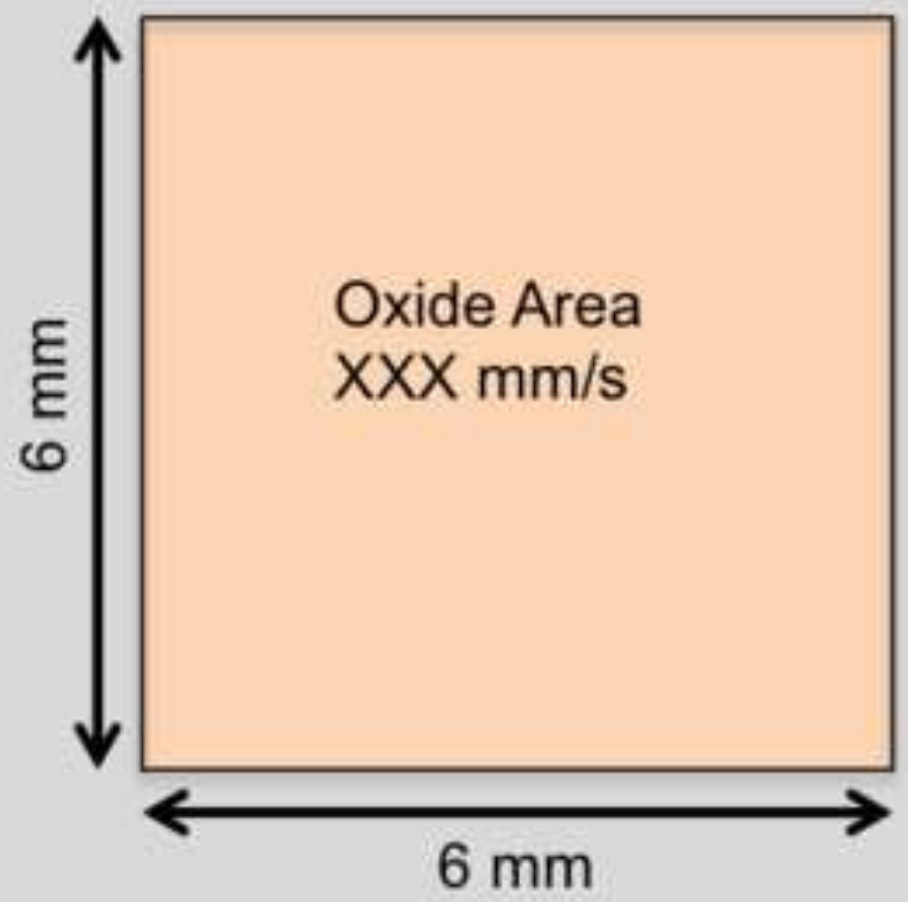



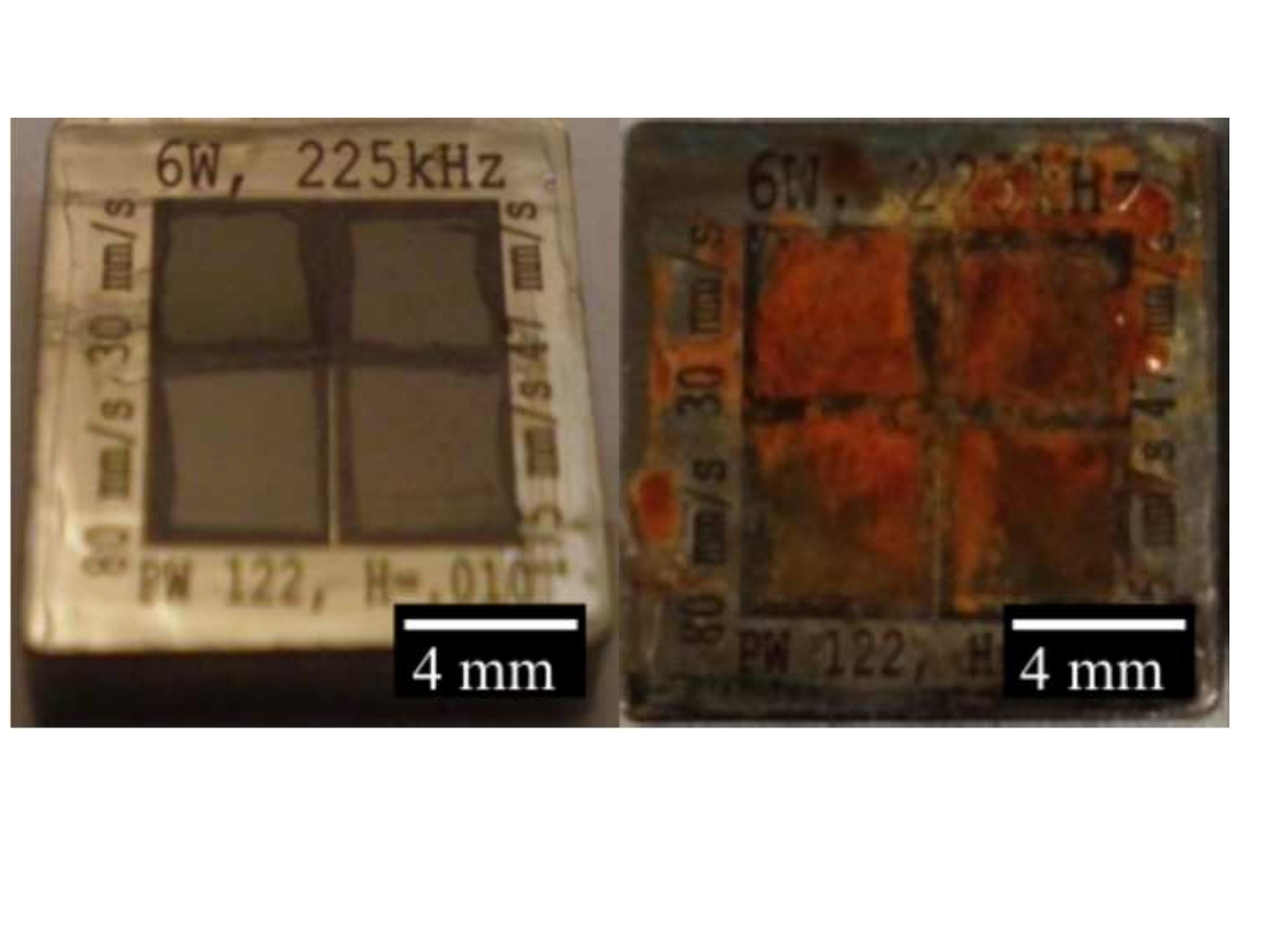

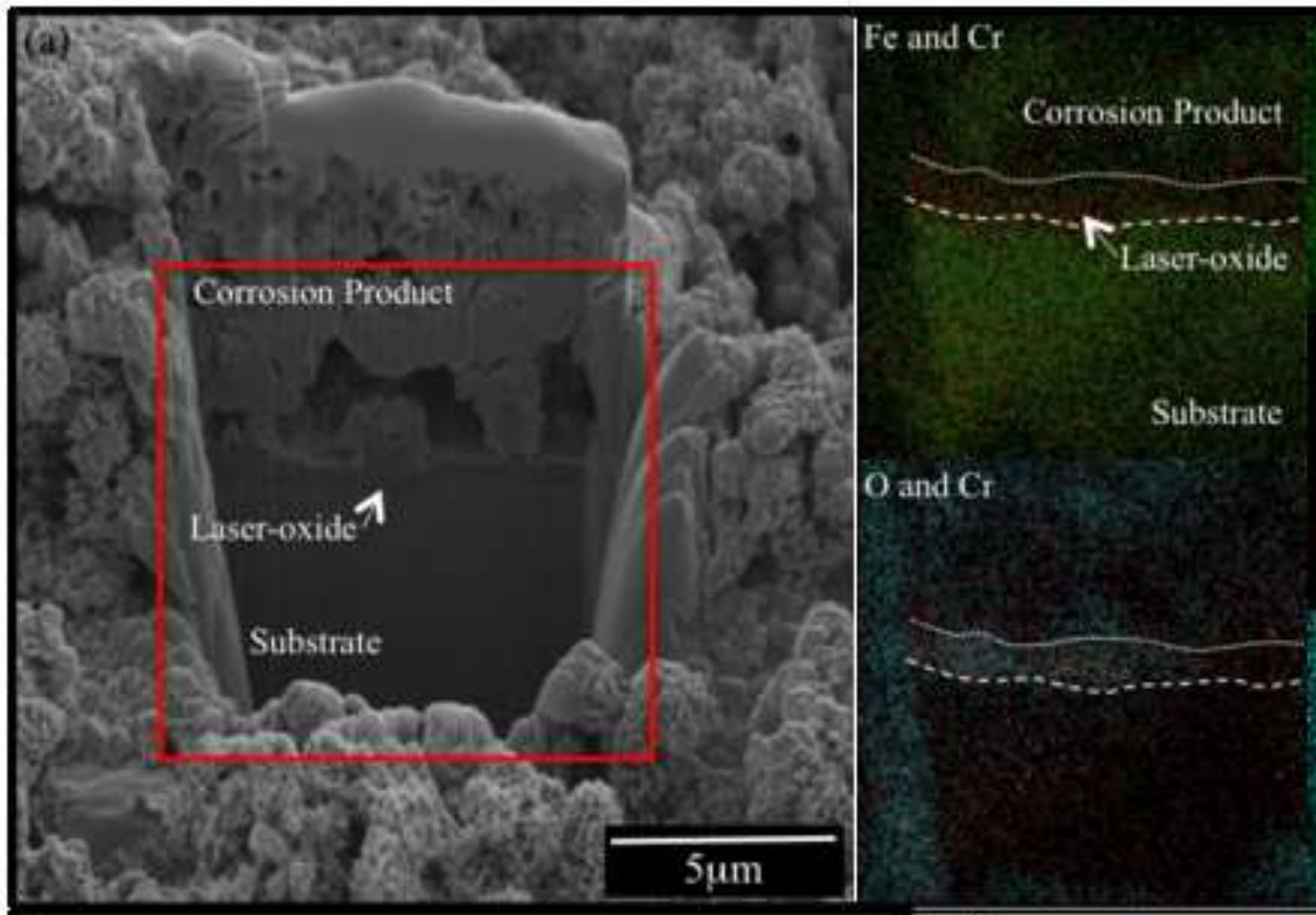

Fe
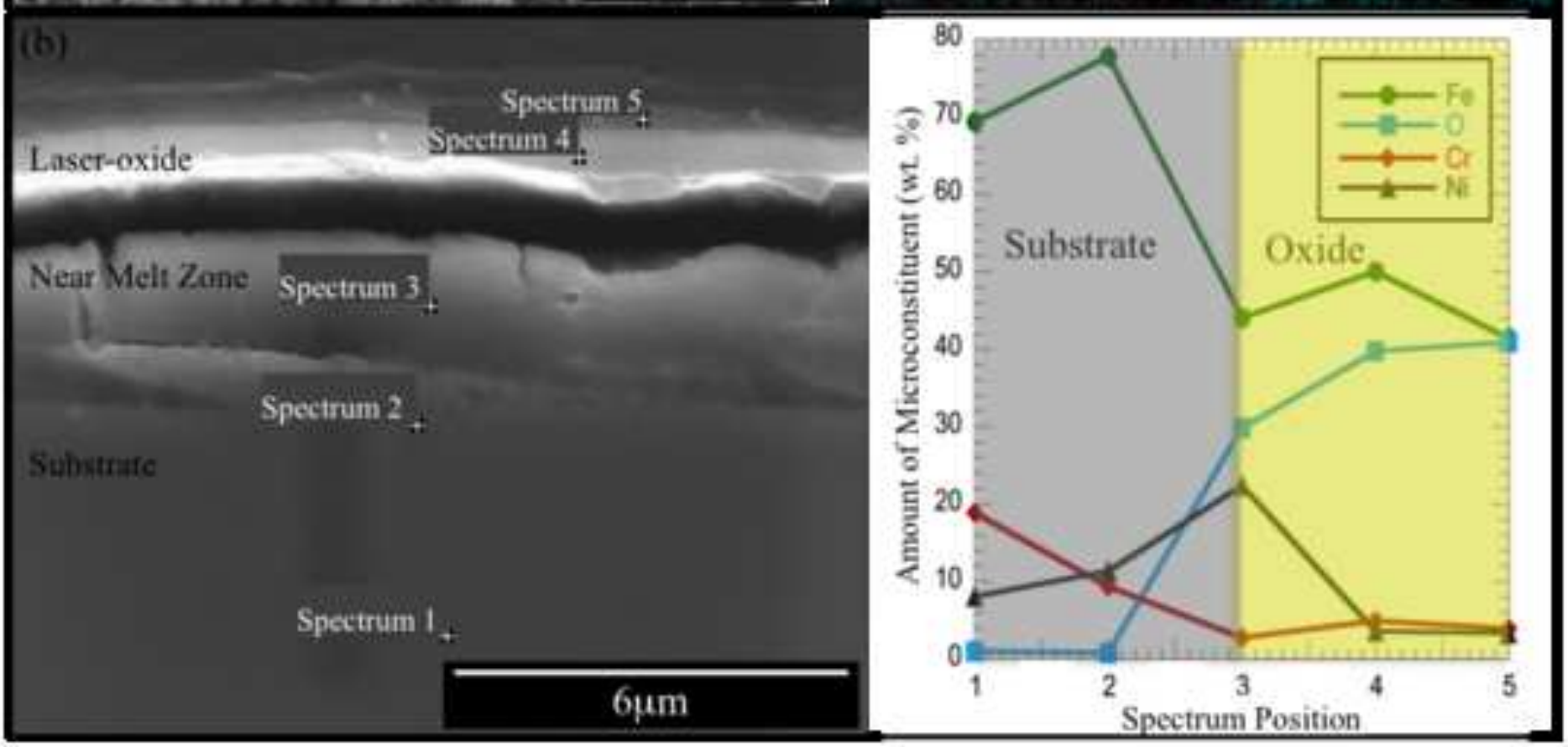

Spectrum 1.

and $\mathrm{Cr}$

Substrate

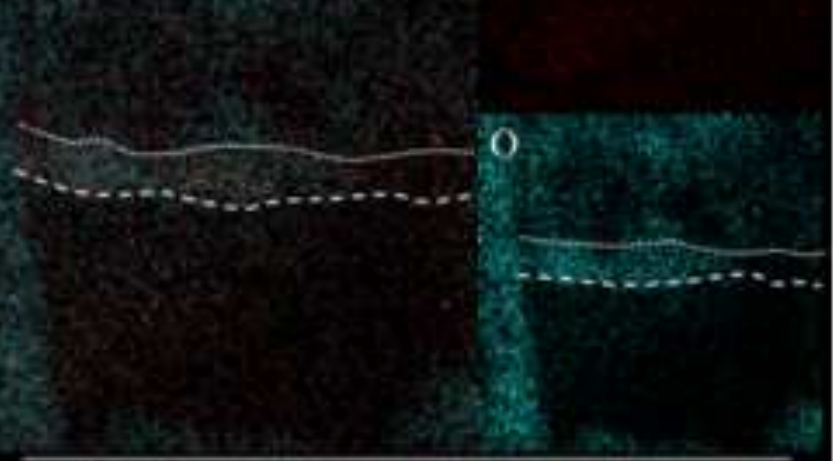

Spectrum 2

Substrarc
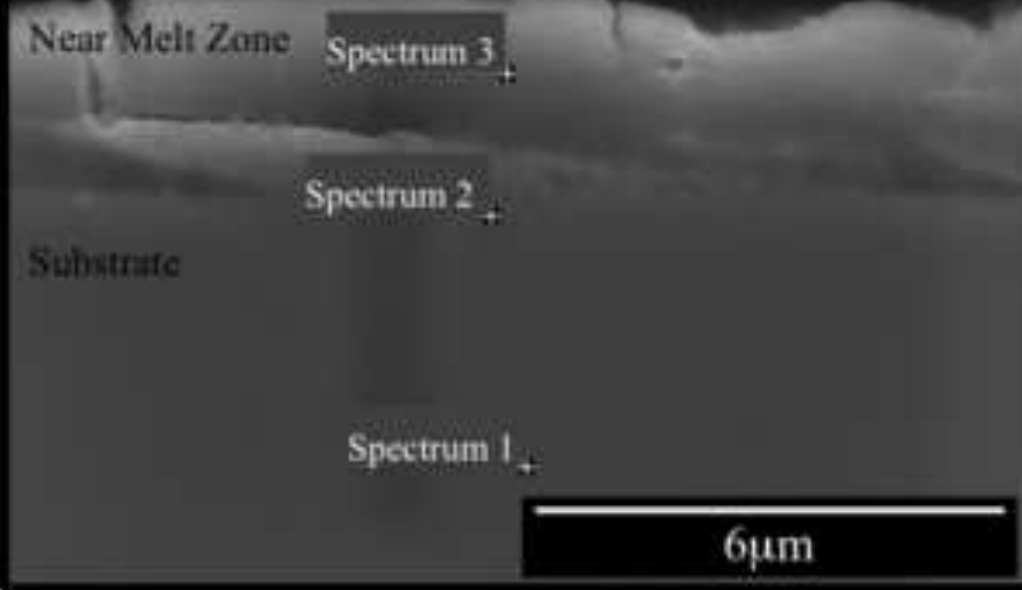

\section{$\mathrm{Cr}$}

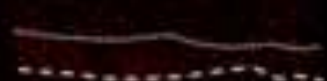

$$
+
$$
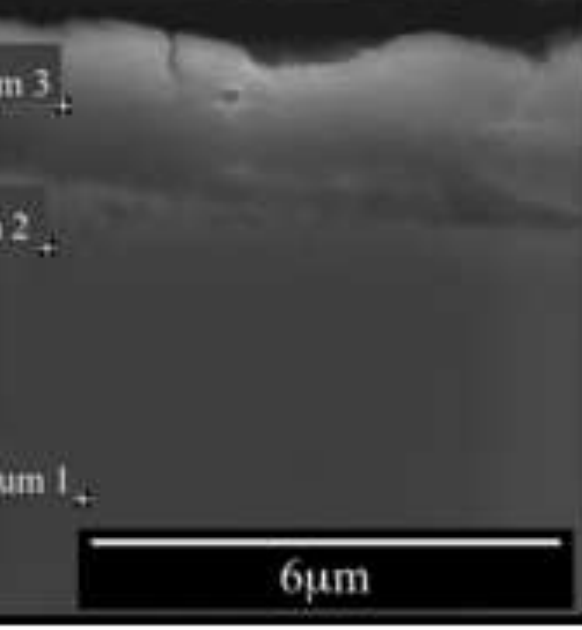

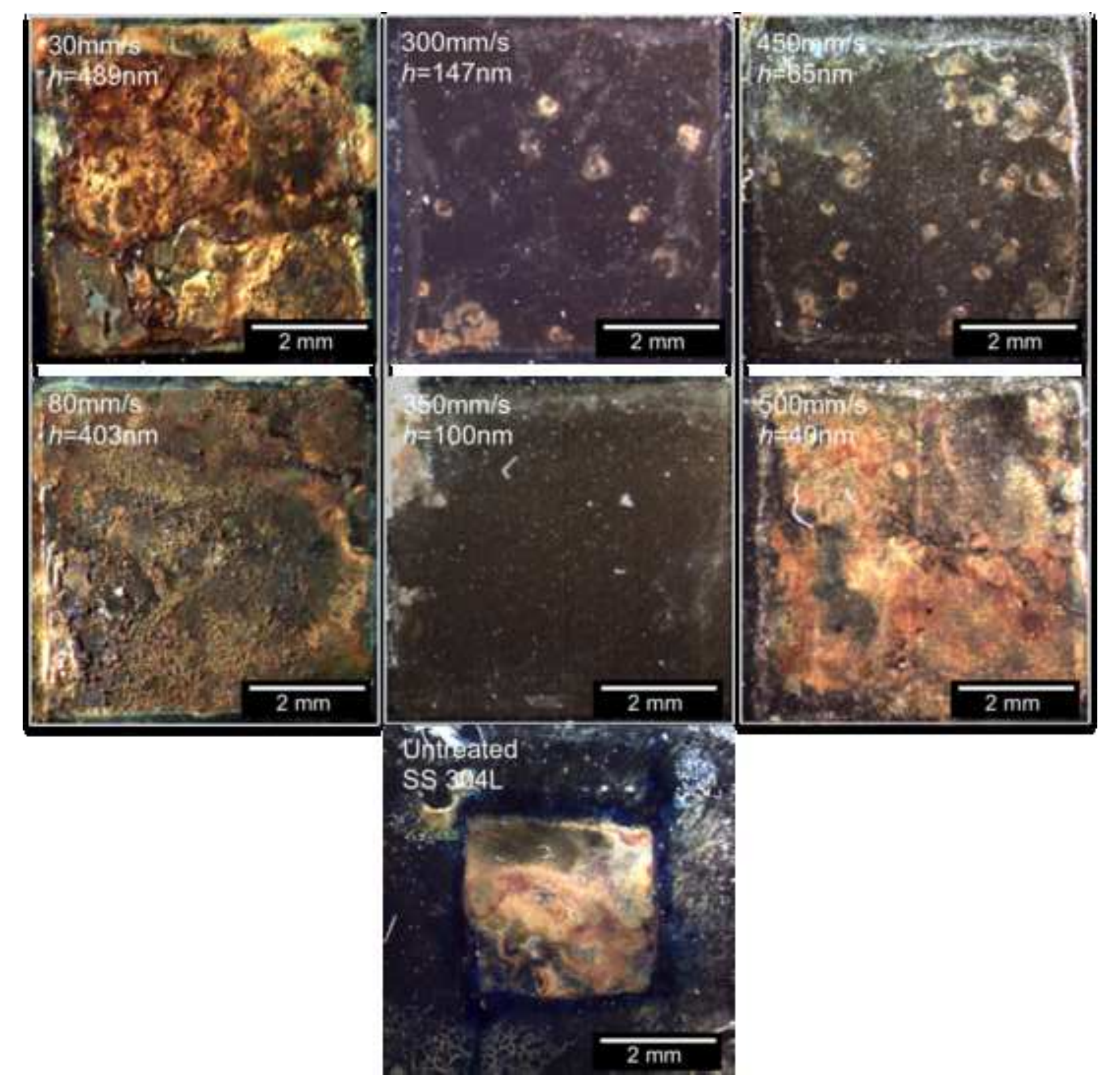

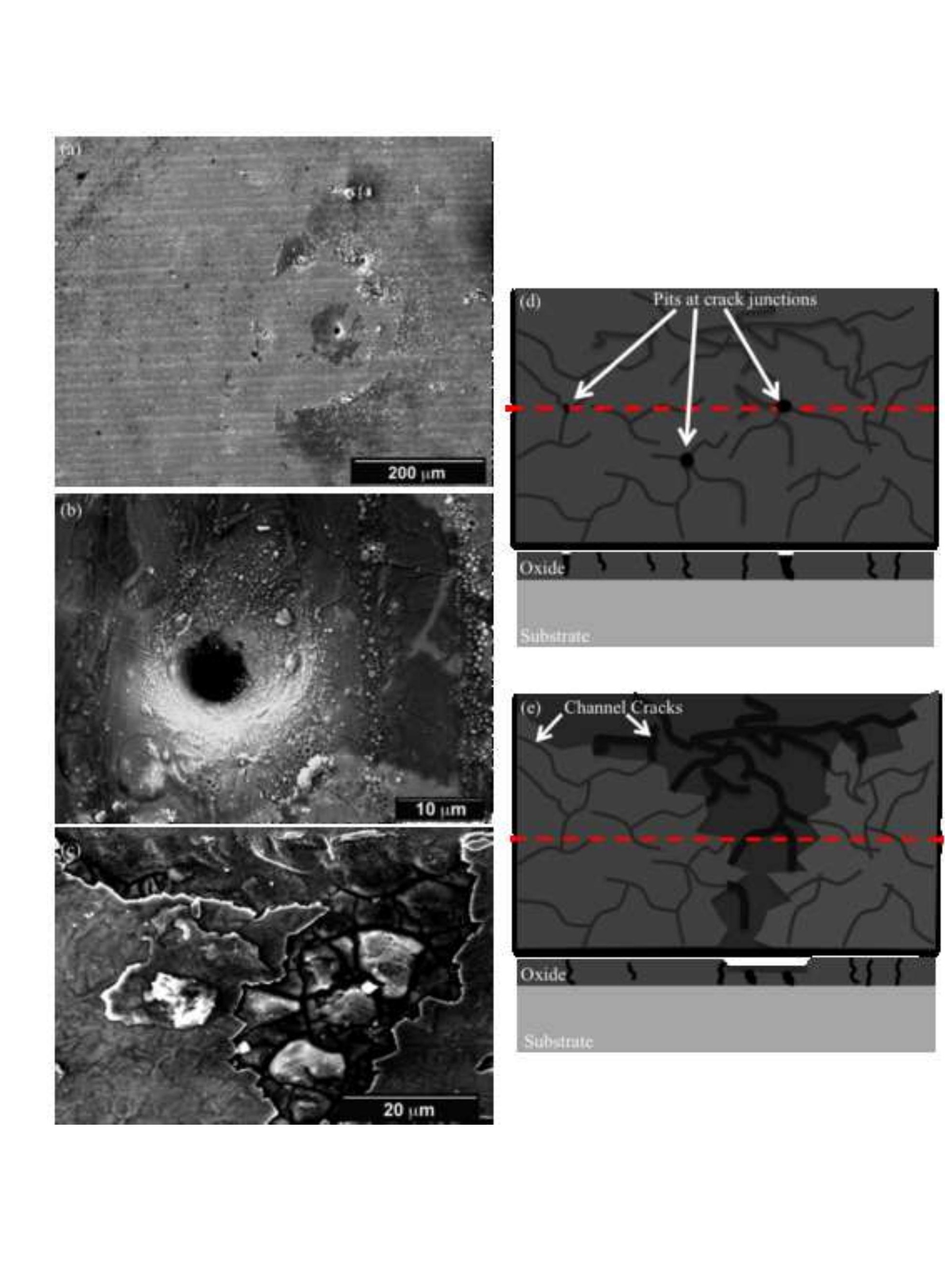

Figure
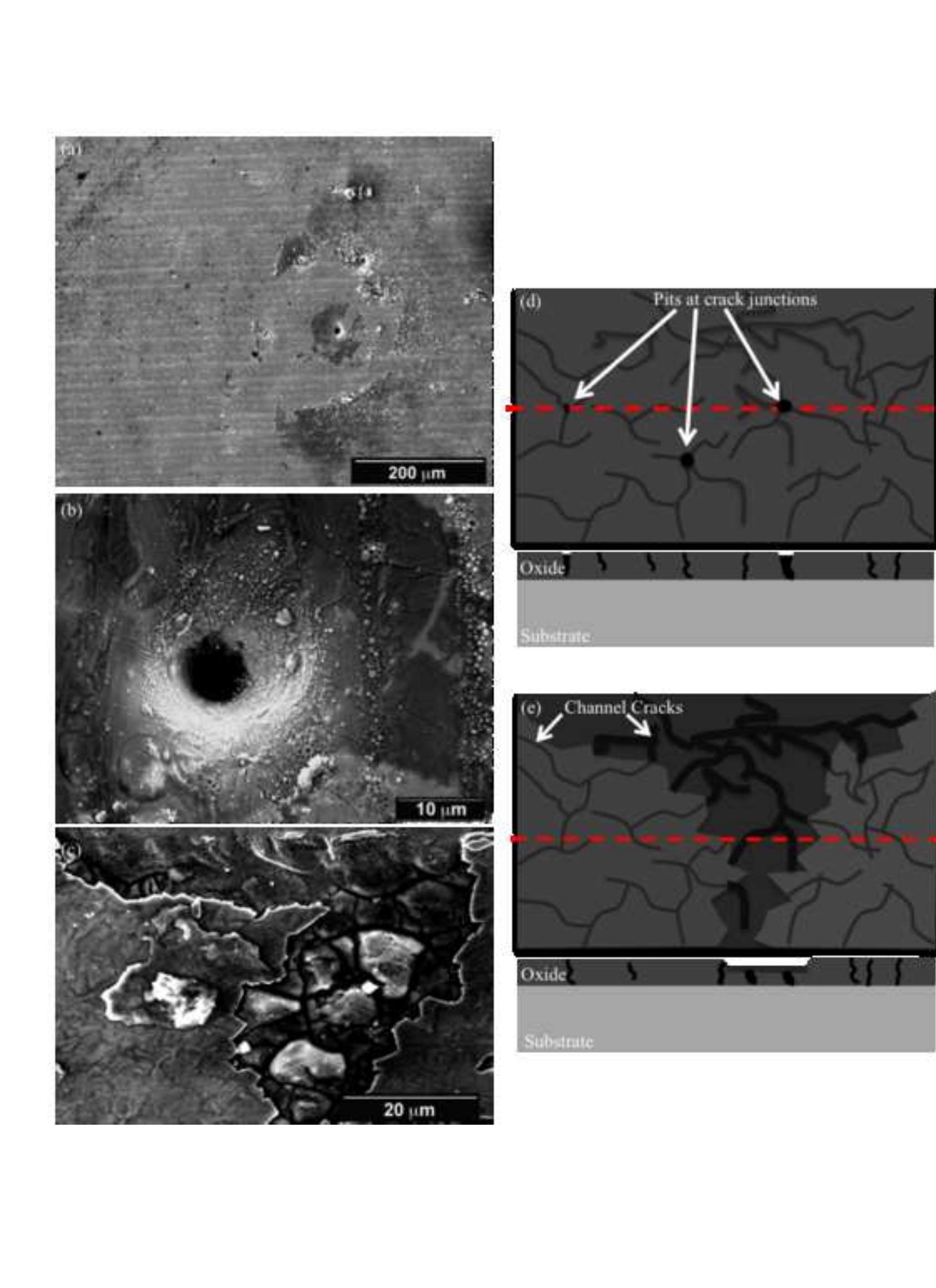

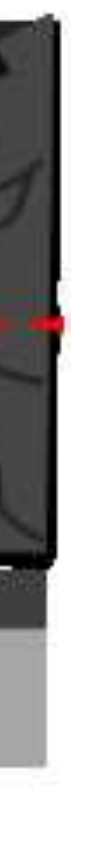



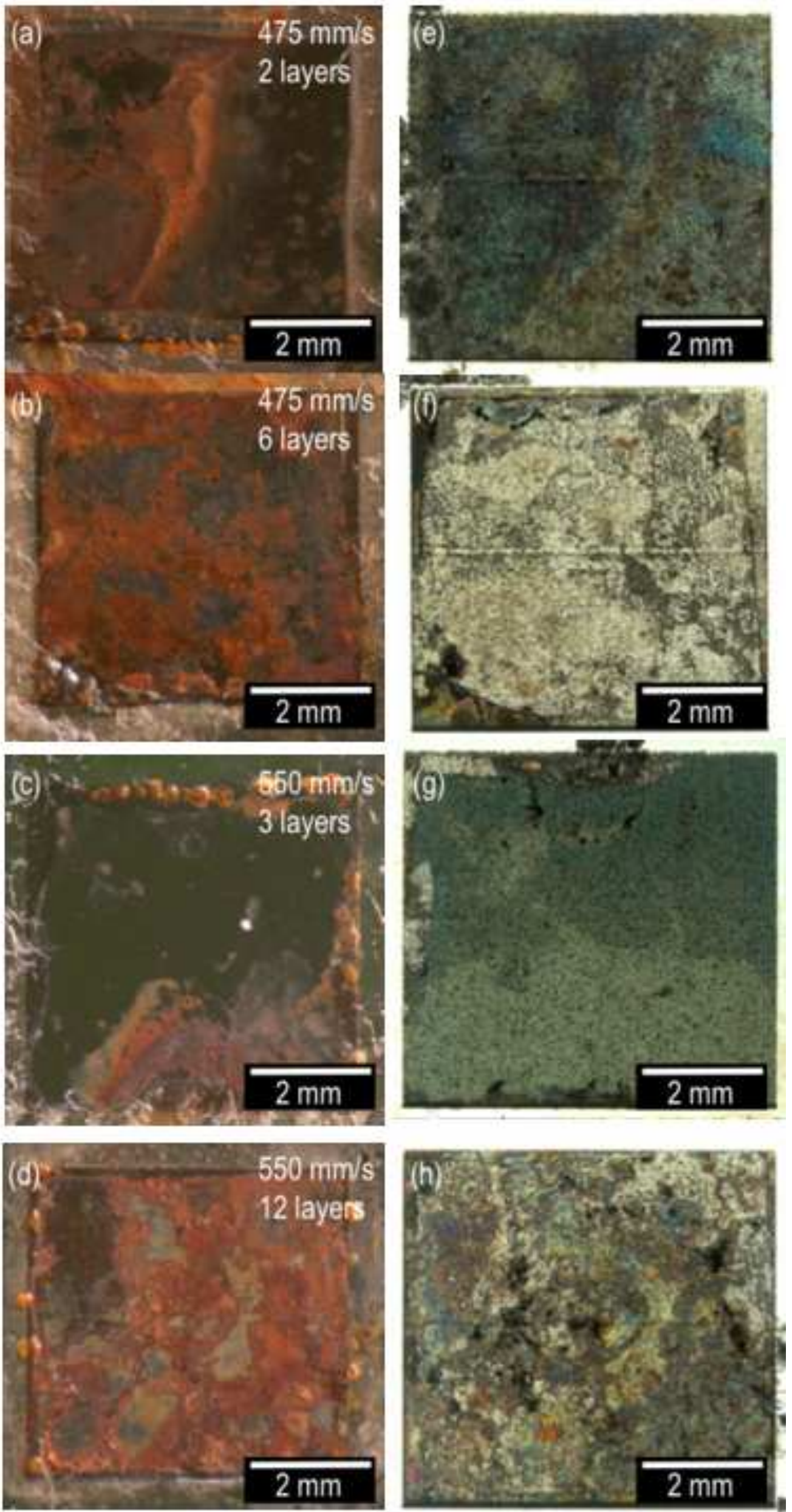

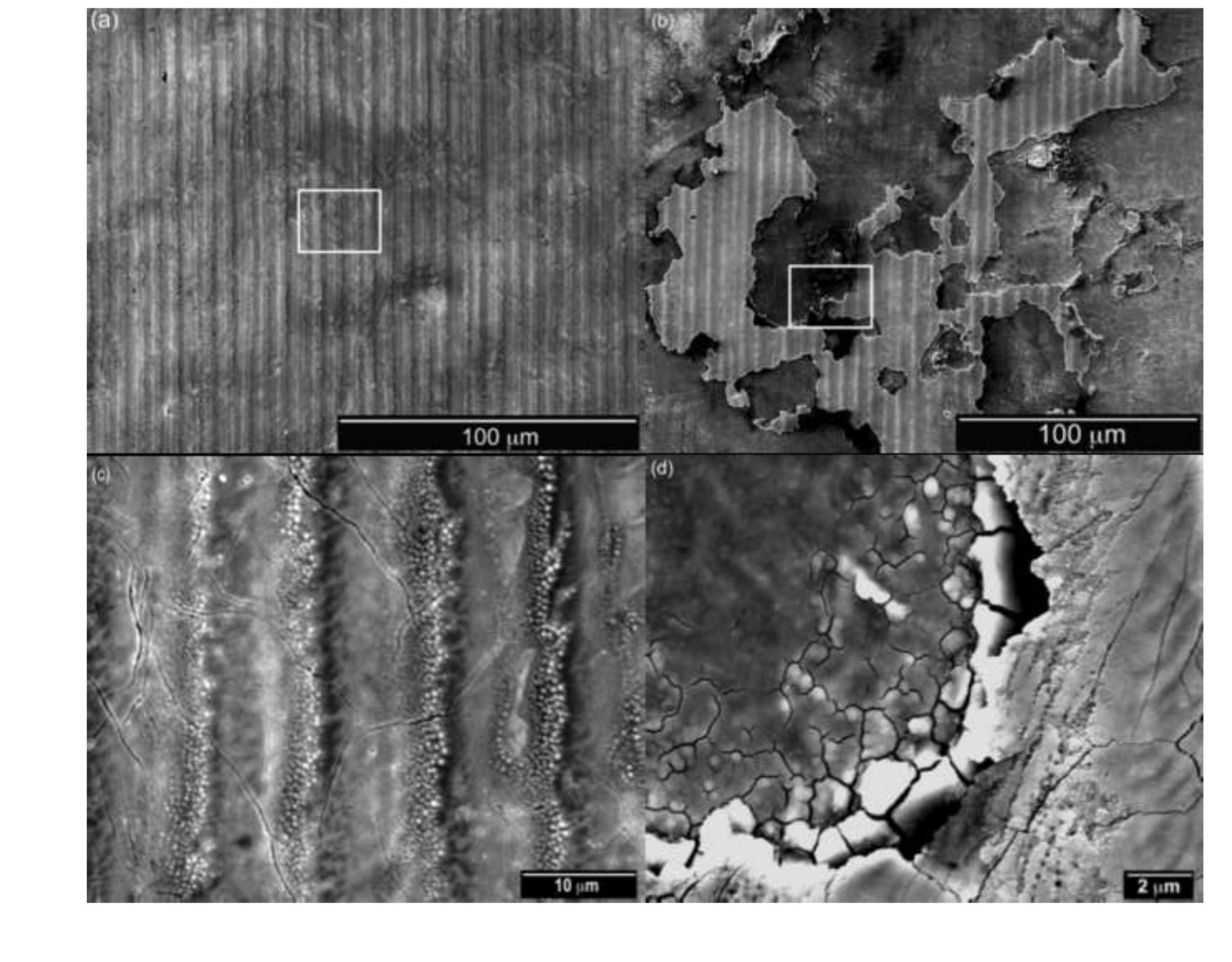

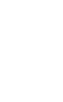
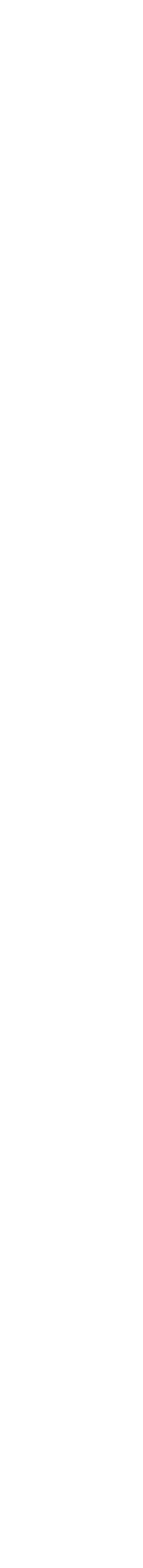


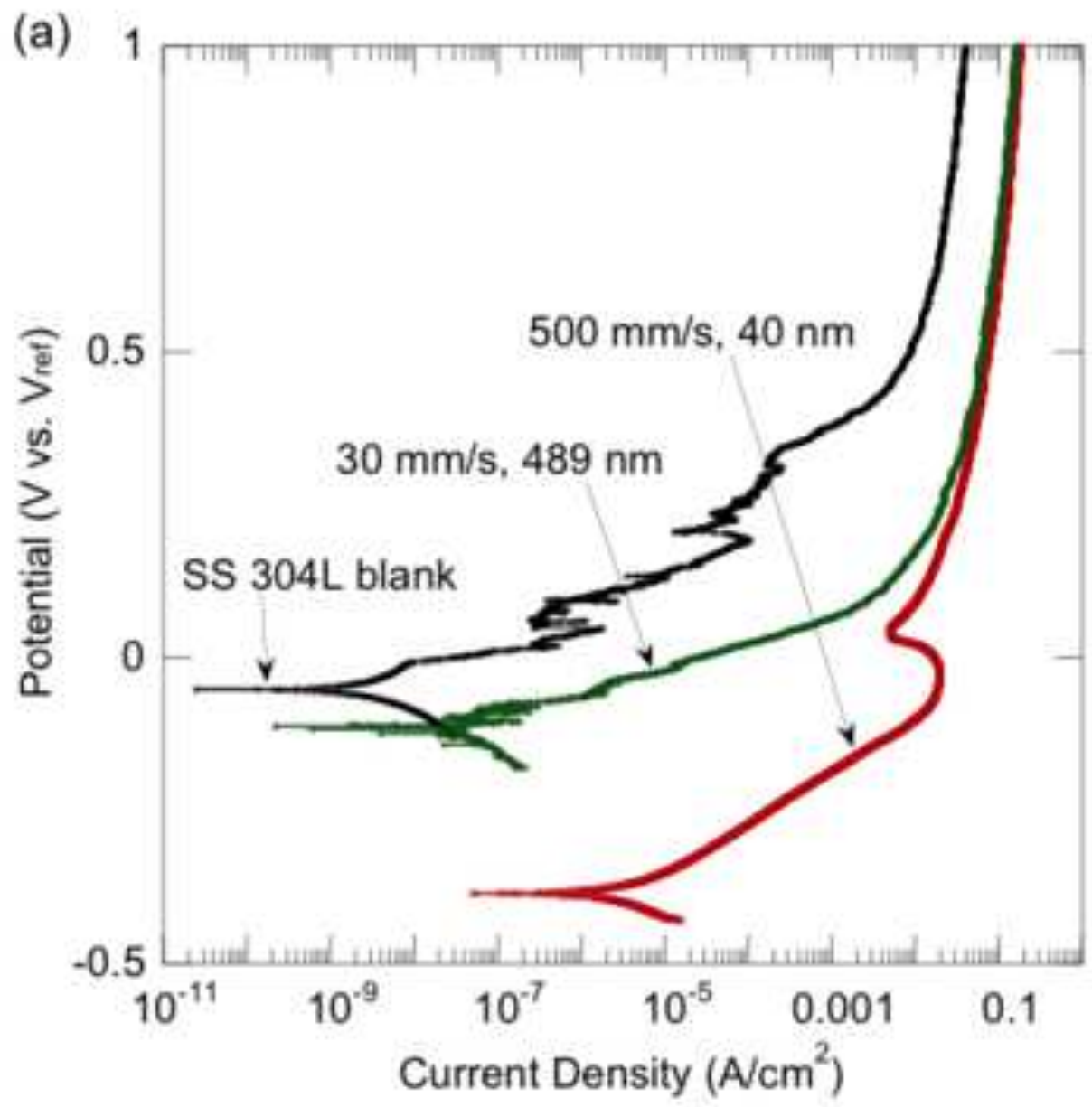

(b)

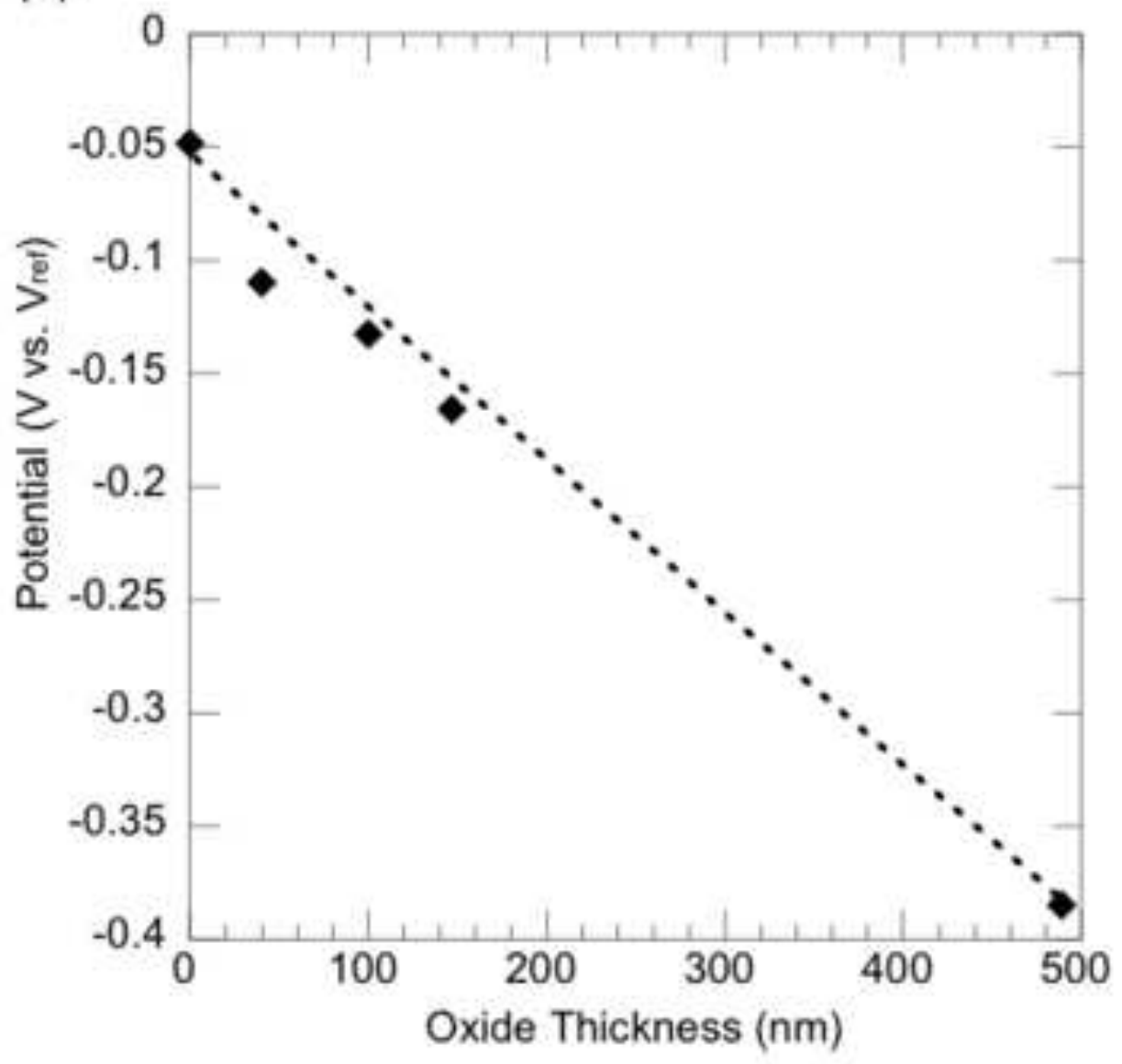




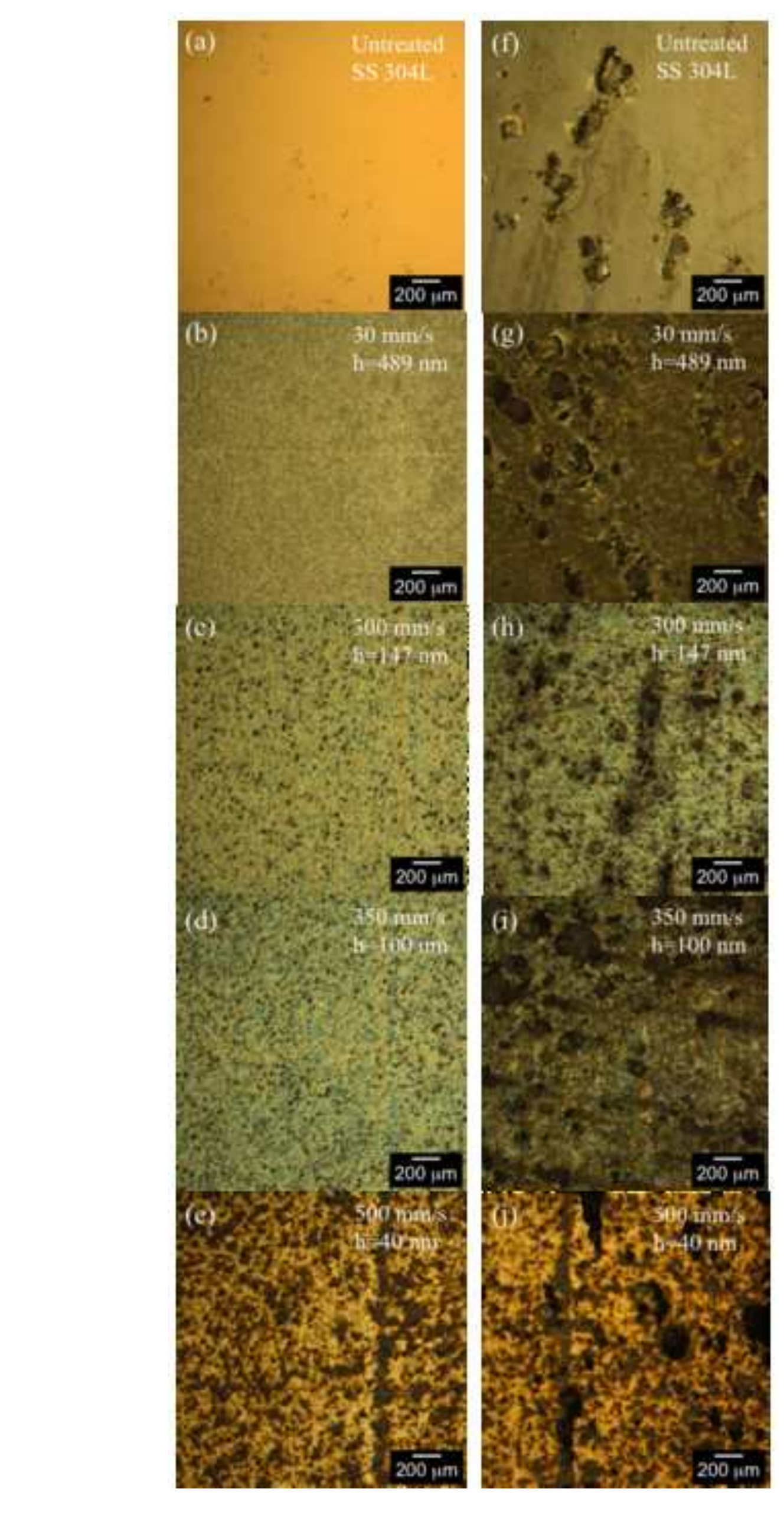

Figure 9

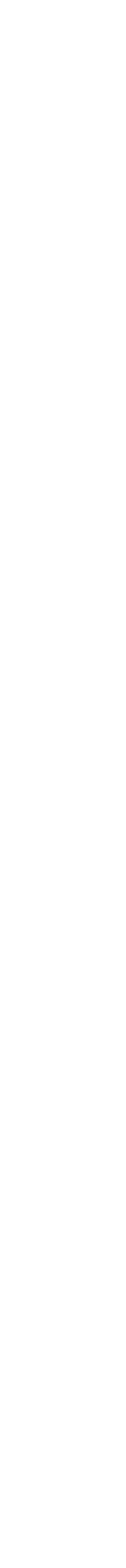

\section{Figure 9}


(a)

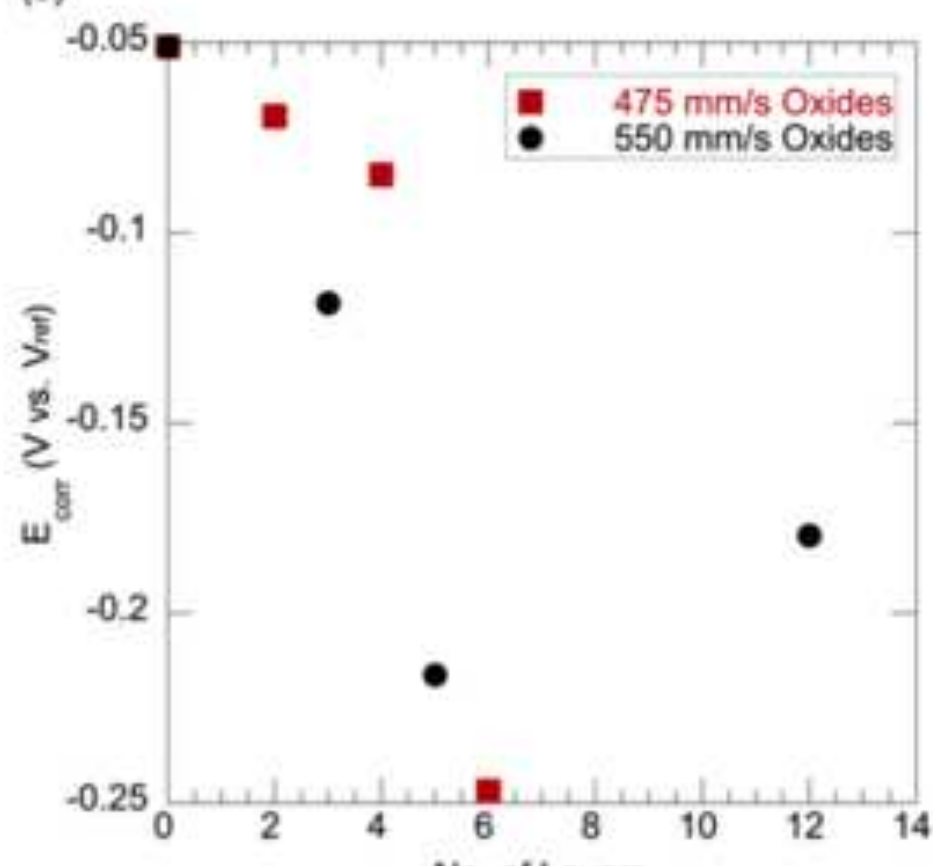

(b)

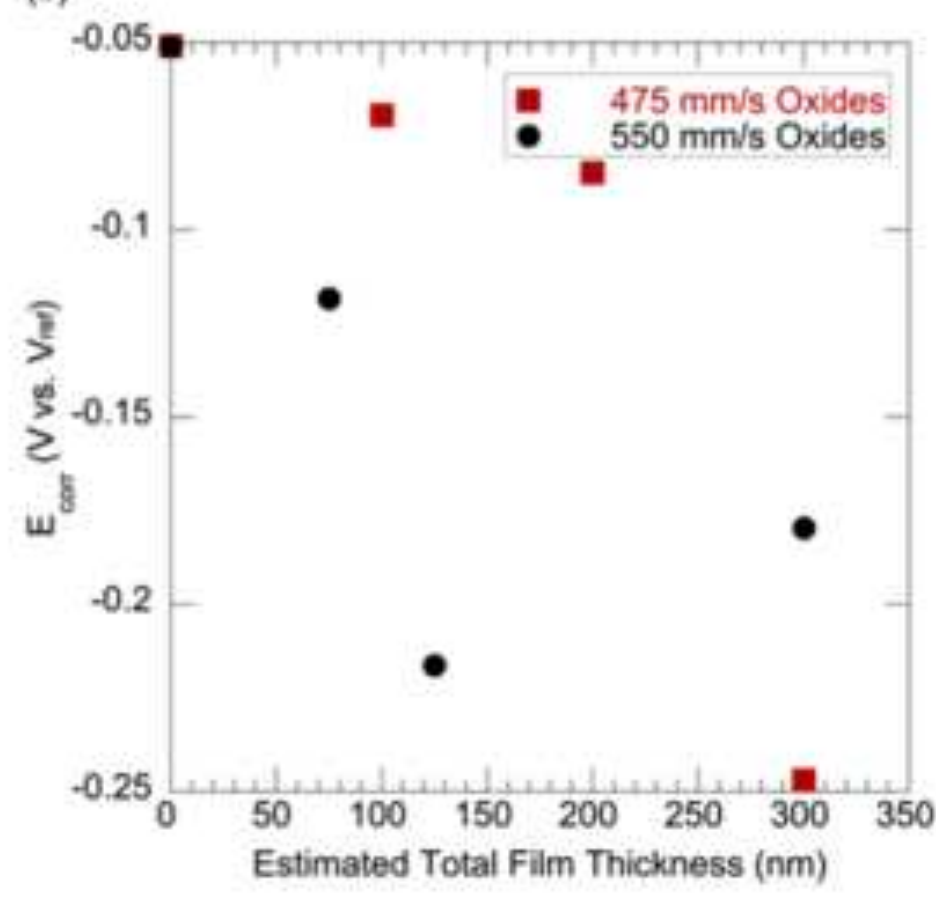

(c)

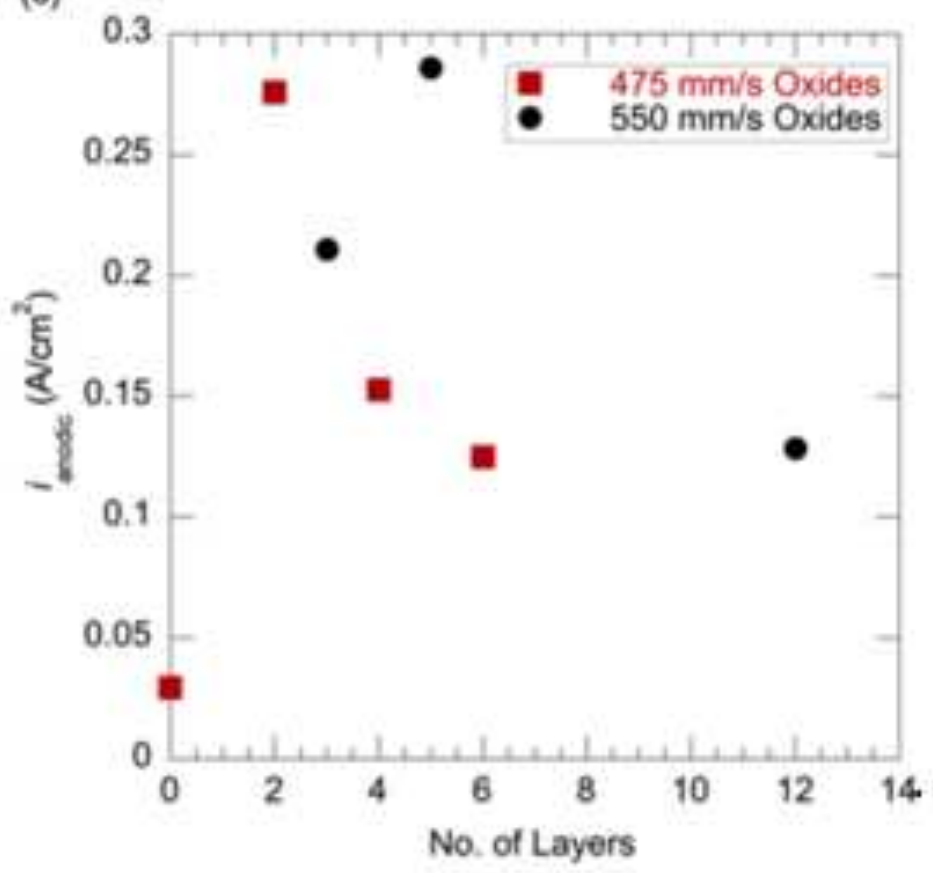

(d)

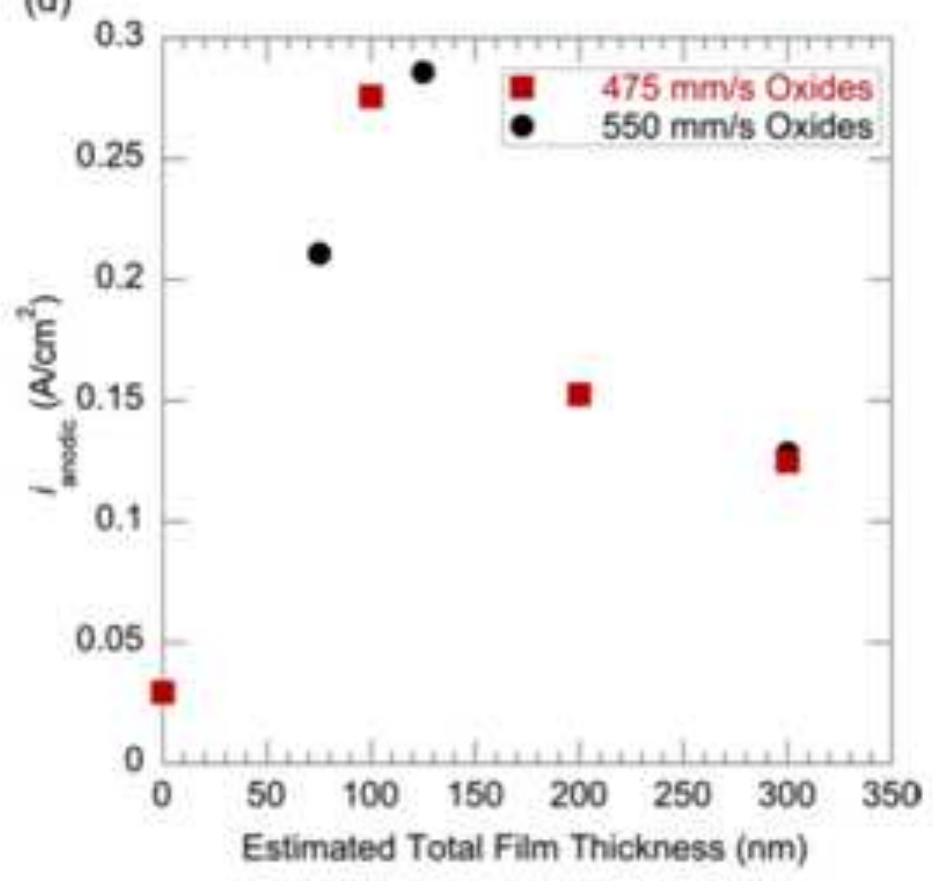




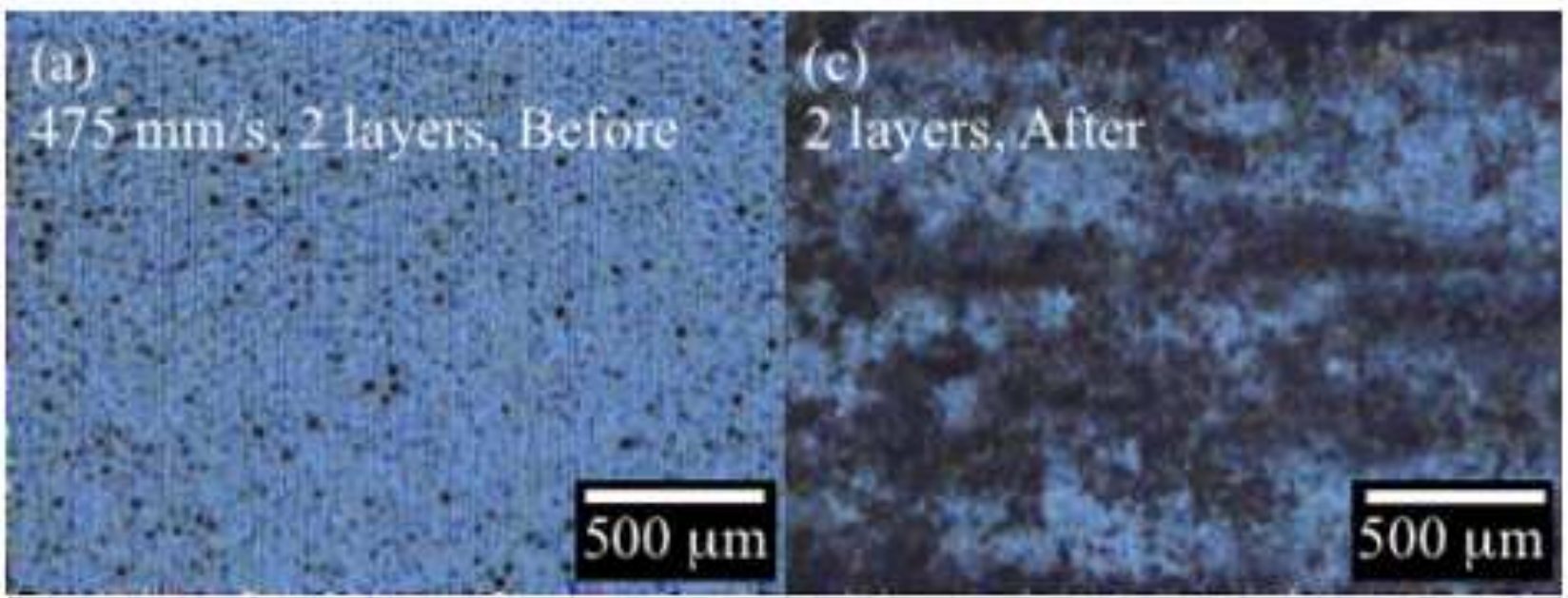

(b)

$475 \mathrm{~mm} / \mathrm{s}, 6$ layers, Before

(f) 6 layersidfer of:

als ox
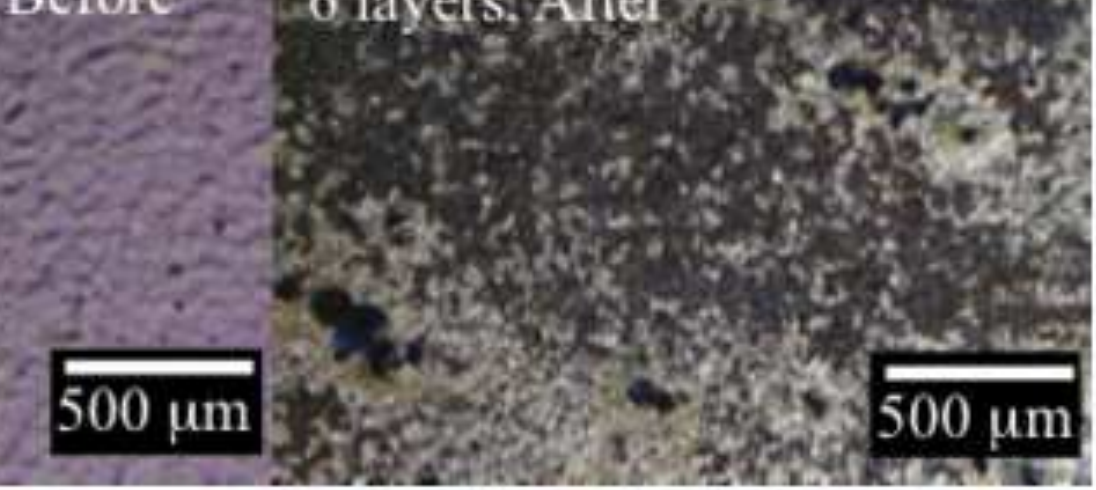

(b)

$550 \mathrm{~mm} / \mathrm{s}, 5$ layers, Before

(d)

sises

5thyers Aftei

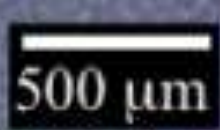

(d)

$550 \mathrm{~mm} / \mathrm{s}, 12$ layers. Before

(h)

12 layers, After
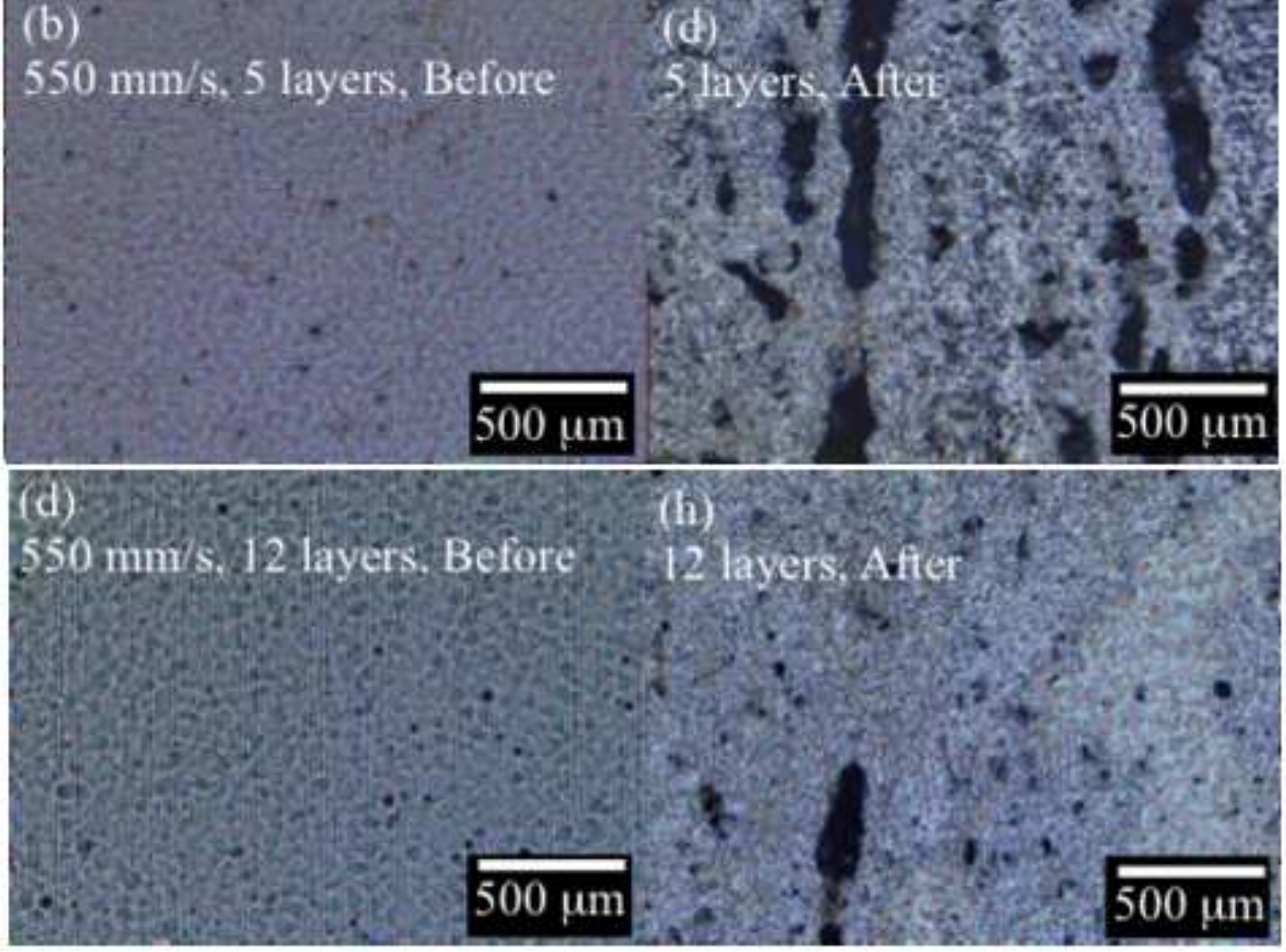